2019-07-01

\title{
Jurassic shift from abiotic to biotic control on marine ecological success
}

Eichenseer, $\mathrm{K}$

http://hdl.handle.net/10026.1/14472

10.1038/s41561-019-0392-9

Nature Geoscience

Nature Research

All content in PEARL is protected by copyright law. Author manuscripts are made available in accordance with publisher policies. Please cite only the published version using the details provided on the item record or document. In the absence of an open licence (e.g. Creative Commons), permissions for further reuse of content should be sought from the publisher or author. 


\section{S1. ASI uncertainty and components}

$\mathrm{Mg} / \mathrm{Ca}$ data. A variety of proxies have been developed to reconstruct the original $\mathrm{Mg} / \mathrm{Ca}$ ratio of past seawater. These include abiotic proxies, such as the composition of fluid inclusions in halite ${ }^{72-75}$ or the $\mathrm{Mg}$-concentrations in carbonate veins from Mid-Ocean ridge flanks ${ }^{76}$, and biotic proxies based on the calcareous skeletons of echinoderms ${ }^{77-79}$, rudists ${ }^{80}$, and foraminifera ${ }^{81,82}$. While together these proxies reflect the general pattern of aragonite-calcite sea oscillations first described by Sandberg $(1983)^{10}$, there is substantial spread between different proxies and even between different measurements of the same proxy (e.g. for fluid inclusion data; see Fig. S1a). As each proxy has different underlying assumptions, it is difficult to directly compare different proxies. Furthermore, the time-coverage of existing proxy data is very scattered with a noticeable paucity of data in the lower-mid Palaeozoic (Fig. S1a).

Among existing proxies, echinoderm skeletal remains have perhaps the highest potential to eventually provide a densely sampled continuous Phanerozoic record of a single proxy. However, the suitability of echinoderms skeletal remains for reconstructing seawater $\mathrm{Mg} / \mathrm{Ca}$ ratios has been questioned as magnesium concentrations significantly vary within individual skeletons ${ }^{83}$, are dependent on the food source ${ }^{84}$, and do not always mirror expected secular $\mathrm{Mg} / \mathrm{Ca}$ trends even in very well-preserved specimens ${ }^{85}$.

In addition to proxy records, various modelling approaches have been developed to reconstruct the $\mathrm{Mg} / \mathrm{Ca}$ ratio of past seawater ${ }^{16,22,86-88}$, (see Fig. S1a). All models are to some degree informed by proxy data, with some using in-model proxy calibrations as part of their approach (e.g. Farkaš et al. 2007; Arvidson et al. 2013). In the latter approach parts of the time series lacking proxy data are strongly biased by the closest proxy data, which is a particular problem for the Palaeozoic. To calculate the $\mathrm{CaSO}_{4}$ flux in the model by Arvidson et al. (2013), for example, the fluid inclusion data by Lowenstein et al. (2003) are used. With only five Palaeozoic data points (one each for the Cambrian, Silurian, and Devonian, and two for the Permian). The resulting Phanerozoic $\mathrm{Mg} / \mathrm{Ca}$ curve has a smooth sinusoidal shape that does not to track stage-scale oscillations.

The Farkaš et al. (2007) model uses a combination of fluid inclusion data ${ }^{72,74}$, echinoderms ${ }^{79}$, and rudists $^{80}$. Given the above mentioned uncertainties about echinoderms as $\mathrm{Mg} / \mathrm{Ca}$ proxy, and the overall challenge of directly comparing different proxies, we did not consider this model any further.

The models of Berner 2004 and of Demicco et al. 2005 do not rely on proxy data as an internal model component, but compare model outputs with proxy data (in the Berner (2004) model, starting conditions were adjusted based on how well the model output fitted the Lowenstein et al. (2001) and Horita et al. (2002) fluid inclusion data). Both are similar in their relative timing of changes of the $\mathrm{Mg} / \mathrm{Ca}$ ratio as they both rely on the same seafloor production curve ${ }^{89}$. However, Berner's (2004) forward modelling underestimates modern seawater $\mathrm{Mg} / \mathrm{Ca}$ ratio. By contrast, Demicco et al. (2005) used backwards modelling, starting with the major ion composition of modern seawater and incorporates reactions along the cooler mid-ocean ridge flanks.

We thus use the $\mathrm{Mg} / \mathrm{Ca}$ ratio obtained from model A in Demicco et al. (2005) for our estimation of ASI. For comparison we show below how similar the ASI is when based on the Demicco et al. (2005) and the Berner (2004) models (Fig. S1b), that that linear regression and CCM analysis of SCORara and ASI based on both these models comes to very similar results (Fig. S2, S4b). 
(a)

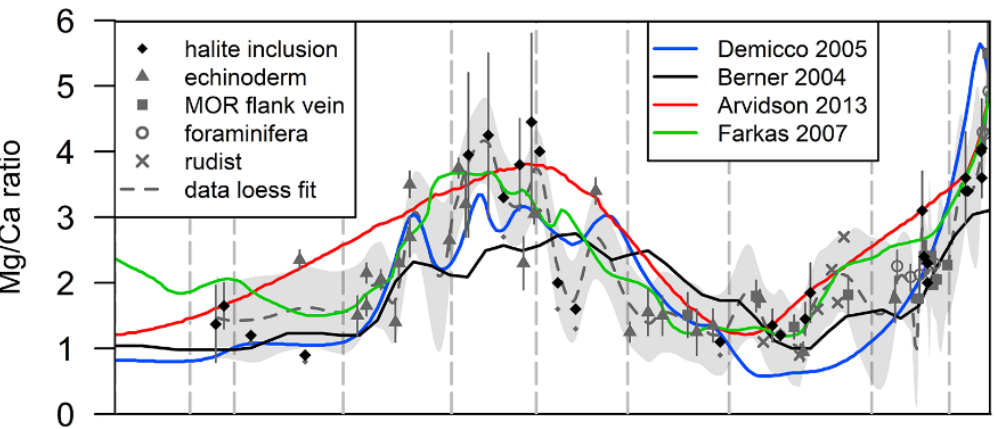

(b)

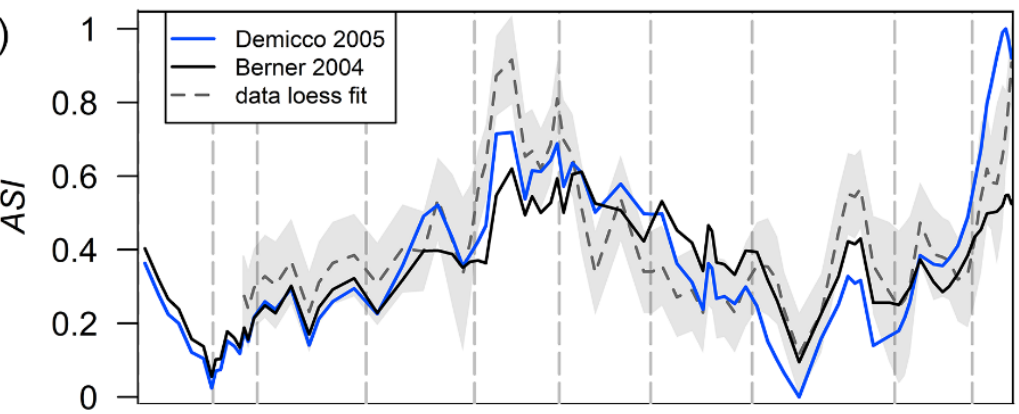

(c)

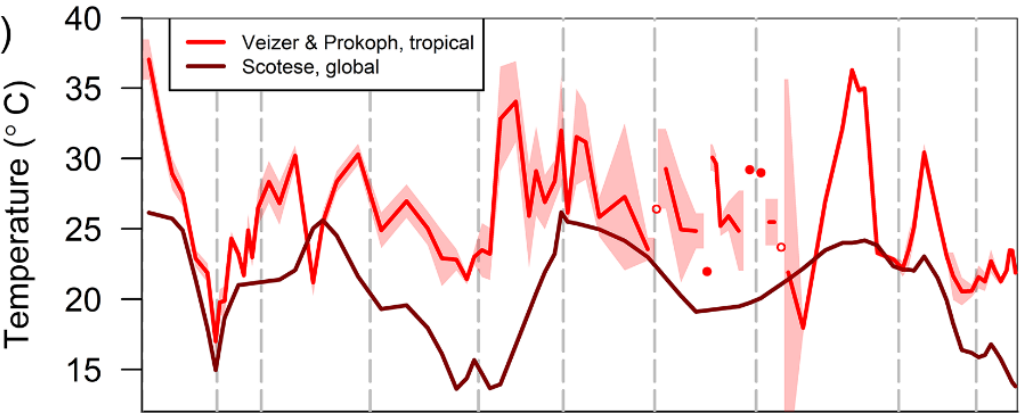

(d)

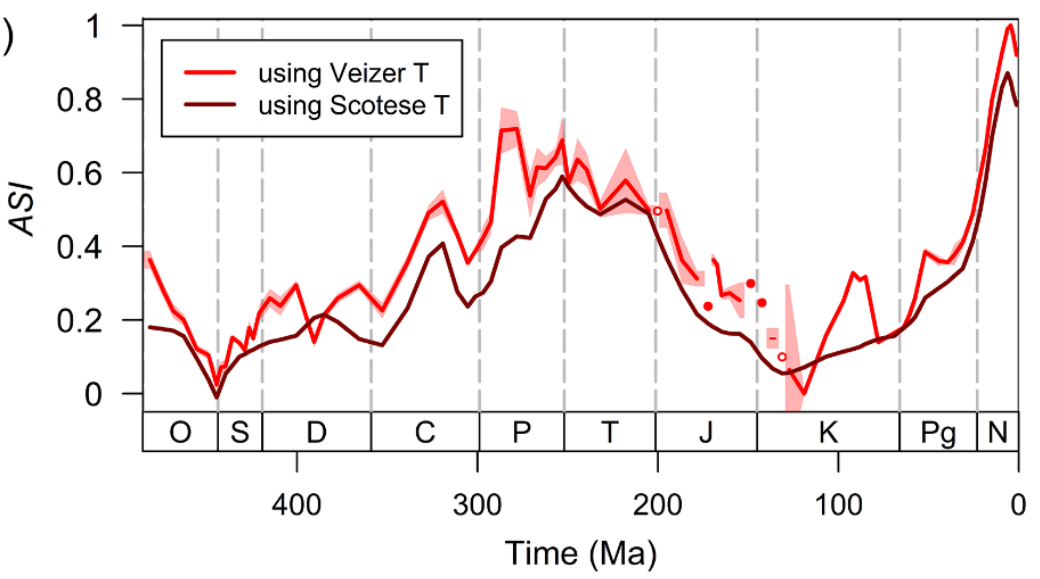

Figure S1: Alternative temperatures and $\mathrm{Mg} / \mathrm{Ca}$ ratios

(a) $\mathrm{Mg} / \mathrm{Ca}$ ratios from models of Demicco et al. (blue), Berner (black), Arvidson et al. (red) and Farkas et al. (green) and proxy data from halite inclusions (diamond) ) $^{72-75,90-92}$, echinoderm skeletons ${ }^{77,78}$ (triangle), mid ocean ridge flank veins ${ }^{76}$ (square), foraminifera tests ${ }^{81,82}$ (circle), and rudist shells ${ }^{80}$ (cross). Error bars denote uncertainties where given, the tiny dots are fluid inclusion $\mathrm{Mg} / \mathrm{Ca}$ ratios with an alternative calcium and sulphate ion product assumption. The dashed line denotes a locally estimated scatterplot smoothing (LOESS) regression with span $=0.1$, based on all proxy data, with one standard error around the regression estimate (grey envelope).

(b) ASI calculated using the temperature data of Veizer and Prokoph and the $\mathrm{Mg} / \mathrm{Ca}$ ratios from models of Demicco et al. (blue) and Berner (black). ASI based on the $\mathrm{Mg} / \mathrm{Ca}$ LOESS regression in (b) is shown as dotted grey line, with an error envelope based on one standard error around the $\mathrm{Mg} / \mathrm{Ca}$ estimate.

(c) Mean tropical shallow water temperatures from $\delta^{18} \mathrm{O}$ measurements from a compilation of Veizer and Prokoph (2015) and a few additional data ${ }^{23,93}$ (red) with 2 standard error envelopes (light red), and global average temperatures from Scotese (2016, brown) ${ }^{94}$. 
Stages with only one measurement are drawn as solid dots, stages without observations have been averaged from the neighbouring stages and are shown as circles.

(d) ASI calculated using the Mg/Ca model of Demicco et al. and the temperatures of Scotese (brown) and Veizer and Prokhop (blue), respectively. The light blue area is a 2 standard error envelope based on the temperature data of Veizer and Prokoph (c). Stages with only one measurement are drawn as solid dots. Stages without observations (circles) have been averaged from the neighbouring stages.

Temperature data. The tropical sea surface temperatures we are using are based on over 15,000 $\delta^{18} \mathrm{O}$ measurements compiled by Veizer and Prokoph $(2015)^{23}$ and a few more measurements from a more recent publication ${ }^{93}$, resulting in an almost continuous, stage-level temperature record (Fig. S1d). To test how sensitive our analysis is to potential temperature errors, we compare this data set with an alternative, global temperature curve generated by Scotese $(2016)^{94}$. Although some of the long-term trends, e.g. a temperature drop corresponding to the Late Palaeozoic ice age feature in both curves, the Scotese (2016) curve shows a lot less short term variation, which results in a smoother ASI curve (Fig. S1c).

ASI sensitivity test. To test how robust the relationship between ASI and SCOR ara is to differences in ASI resulting from different models or data, we calculated an ASI from each of the two temperature curves from Fig. S1a and two of the $\mathrm{Mg} / \mathrm{Ca}$ models from Fig. S1b. We conducted linear regressions in expanding windows of $\mathrm{SCOR}_{\text {ara }}$ against the four resulting ASI combinations. The regression patterns with the alternative ASI combinations (Fig. S2b-d) are encouragingly similar to the patterns produced by our initially proposed ASI (Fig. S2a). The Scotese (2016) temperatures barely change the correlation in the Palaeozoic, but yield a stronger correlation in the early Mesozoic. The Berner model results in a weaker correlation in the early Mesozoic when paired with the Veizer and Prokoph (2015) temperatures, but the loss of positive correlation after the early Mesozoic can still be seen. The negative correlation in the later Mesozoic and early Cenozoic with this specific model is likely spurious.

(a)

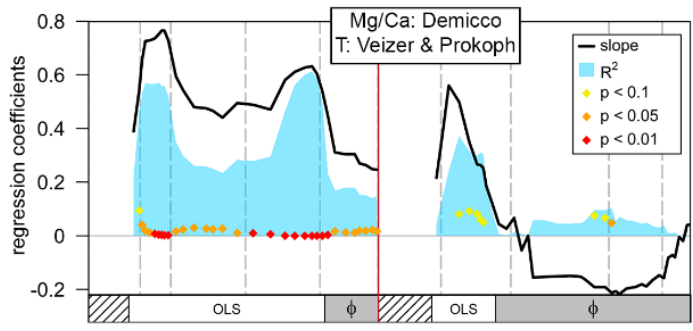

(c)

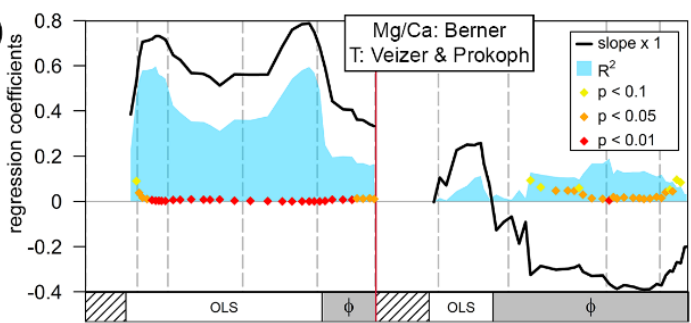

(b)

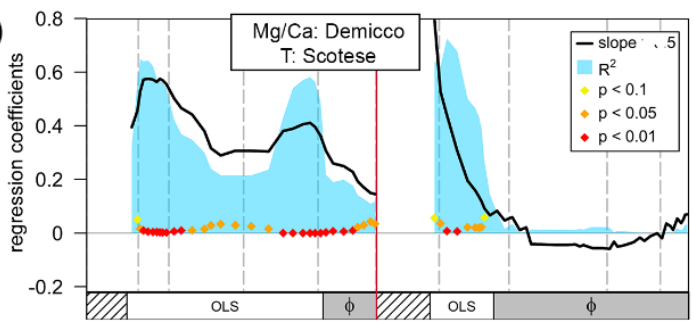

(d)

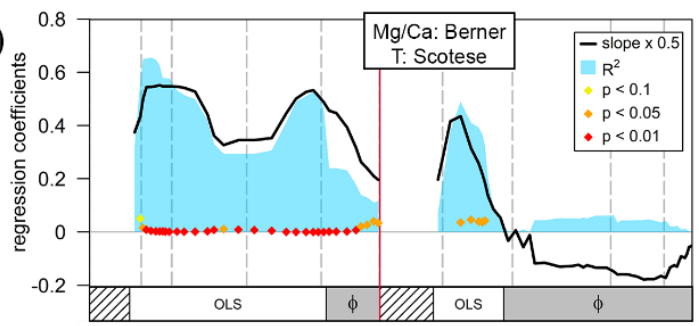

Figure S2: Regression in expanding windows with alternative ASI

Linear models of SCORara against ASI in windows of increasing length in the Palaeozoic and in the Mesozoic - Cenozoic, separately. Slope (black) and $\mathrm{R}^{2}$ (blue) of each model are drawn at the last included stage of the respective window. $p$-values are only shown when they are $<0.1$. All Palaeozoic models start at the first Ordovician stage (Tremadocian), and all Mesozoic - Cenozoic models start with the Early Triassic (Induan). The box at the bottom shows whether the models were generated using ordinary least squares (OLS), or generalised least squares with autoregressive errors $(\phi)$. No models were fitted for intervals with five or less stages (hatched pattern).

(a) ASI was calculated using the $\mathrm{Mg} / \mathrm{Ca}$ ratio of Demicco et al. and the temperatures from Veizer and Prokoph as in Fig. $2 \mathrm{~b}$.

(b) ASI was calculated using the $\mathrm{Mg} / \mathrm{Ca}$ ratio of Demicco et al. and the temperatures from Scotese.

(c) ASI was calculated using the $\mathrm{Mg} / \mathrm{Ca}$ ratio of Berner and the temperatures from Veizer and Prokoph.

(d) ASI was calculated using the $\mathrm{Mg} / \mathrm{Ca}$ ratio of Berner and the temperatures from Scotese. 


\section{$\mathrm{Mg} / \mathrm{Ca}$ and Temperature separately}

To evaluate the relative importance of the two components of the ASI model, $\mathrm{Mg} / \mathrm{Ca}$ ratio and temperature, we assess their independent effect on $\mathrm{SCOR}_{\text {ara. }}$. The $\mathrm{Mg} / \mathrm{Ca}$ model shows little variation in the Ordovician - Devonian, and linear regressions in this time window behave erratic as a consequence (Fig. $3 \mathrm{~b}$ ). With increasing $\mathrm{Mg} / \mathrm{Ca}$ variability in the late Palaeozoic and the early Mesozoic, the correlation patterns inferred with ASI extending to these intervals are similar to the patterns with just $\mathrm{Mg} / \mathrm{Ca}$ ratio. Temperature alone drives the linear correlation in the earlier part of the record, but becomes dominated by $\mathrm{Mg} / \mathrm{Ca}$ ratio from the Carboniferous onwards. CCM results are not limited to linear dynamics and thus may give a better idea of which model component exerts greater control on $\mathrm{SCOR}_{\text {ara. }}$. We find that $\mathrm{Mg} / \mathrm{Ca}$ ratio shows stronger dynamical coupling with $\mathrm{SCOR}_{\text {ara }}$ than temperature does (Fig. S4b), although the analysis is only significant at the $95^{\text {th }}$ confidence level when temperature and $\mathrm{Mg} / \mathrm{Ca}$ ratio are combined to the ASI forcing model which best reflects current understanding of abiotic influences on calcification.

(a)

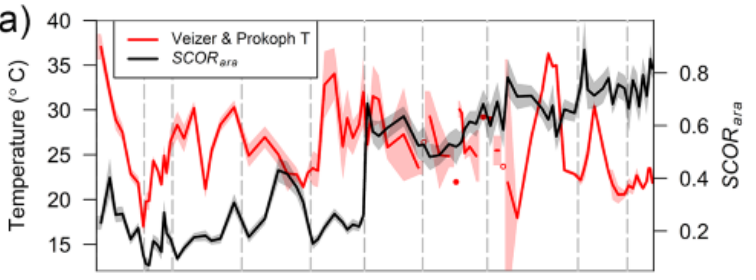

(c)

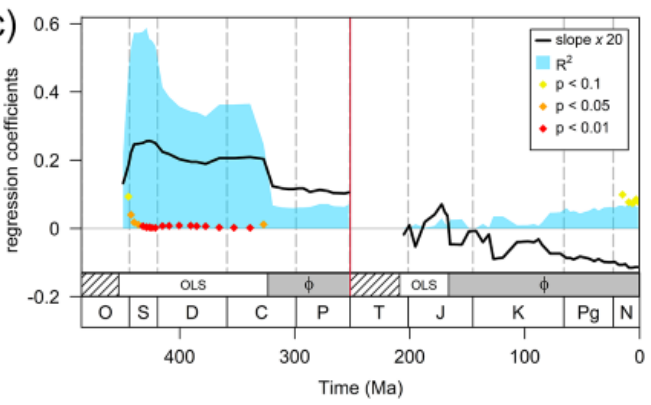

(b)

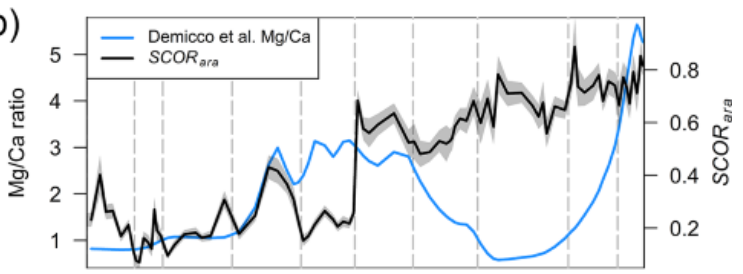

(d)

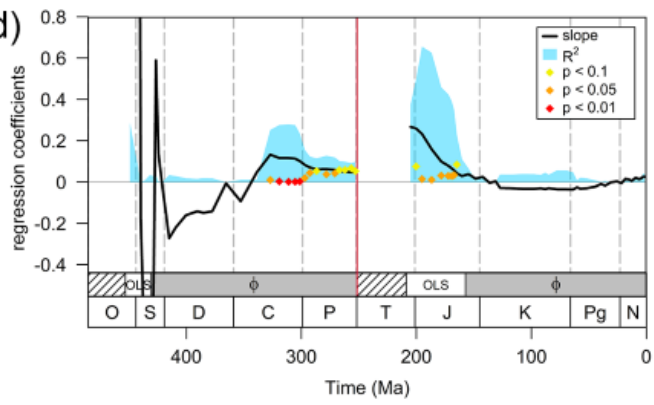

Figure S3: Temperature and $\mathrm{Mg} / \mathrm{Ca}$ separately with SCOR

(a) Mean tropical shallow water temperatures from Veizer and Prokoph as in Fig. S1c (red) and SCORara (black).

(b) Modelled Mg/Ca ratio from Demicco et al. as in Fig. S1a (blue) and SCOR ara (black).

(c) Linear models of SCORara against temperature (a) in windows of increasing length in the Palaeozoic and in the Mesozoic - Cenozoic, separately.

(d) Linear models of SCORara against Mg/Ca ratio (b) in windows of increasing length in the Palaeozoic and in the Mesozoic - Cenozoic, separately.

\section{S2. Convergent cross mapping (CCM)}

In the following, we discuss the application of CCM in the context of our study, starting with a brief outline out the algorithm (see Sugihara et al., 2012 for details), then give a heuristic theoretical basis for the expanding window analysis.

\section{CCM algorithm}

The CCM algorithm works as follows. First, reconstruct the state space for the driver system by a timedelay embedding of the driver time series. Then, pick a point (one point = one sample) on the reconstructed orbit and keep track of its time index in terms of the original time series. Say the point $P_{i}$ with time index $t_{i}$ is picked, with the corresponding scalar point in the driver time series being $D\left(t_{i}\right)$. Next, locate the $\operatorname{dim}+1$ nearest neighbours of $\mathrm{P}_{\mathrm{i}}$ in the reconstructed phase space (forming a dim- 
dimensional simplex enclosing a volume around the point), say their time indices are $t_{k_{-} 1}, t_{k_{-} 2}, \ldots$, $t_{k_{-}(d i m+1)}$. Then, make a prediction of $D\left(t_{i}\right)$ by computing a weighted average of $D\left(t_{k_{-}}\right), D\left(t_{k_{-}}\right), \ldots$ $D\left(t_{k_{-}(d i m+1)}\right)$, where the weights are controlled by the distances between $P_{i}$ and $P\left(t_{k_{-}}\right), P\left(t_{k_{-}}\right), \ldots$,

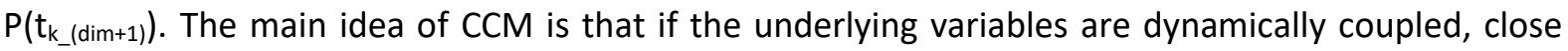
neighbours in the response system should map to close neighbours in the driver system.

\section{Convergence criterion}

CCM uses convergence of prediction skill as the number of points increases to distinguish causation from correlation ${ }^{27}$. For each time series pair, the library used for the analysis, i.e. those data points from the response time series which are used to predict the driver time series, is gradually increased up to the total length of the time series. To determine a minimum time window for which cross mapping is applicable, we consider analyses convergent if the median CCM prediction skill over 500 samples is higher at large library sizes than at lower library sizes. Convergence of an analysis is assessed using a Wilcoxon rank-sum test: if the test for a given time window fails to reject the null at the 0.01 level, we consider the analysis non-convergent. For the shortest time windows, no robust test could be performed, and these analyses are considered non-convergent.

\section{Robustness to data uncertainty}

To explore the robustness of the results when incorporating the uncertainty in the data, we use the uncertainty handling machinery in the UncertainData.jl

(https://github.com/kahaaga/UncertainData.j) Julia package, in combination with the highperformance CrossMappings.jl package (https://github.com/kahaaga/CrossMappings.jl).

\section{Theoretical basis for expanding window analysis}

Due to, for example, secular changes in orbital configuration and time-varying mid-ocean ridge forcing, the Earth system is inherently nonergodic. To interpret the CCM results in a dynamical systems framework, we thus adapt a pullback attractor interpretation of the system, which we heuristically summarise in the following (we refer to Chekroun et al., 2011 for an in-depth introduction to this topic ${ }^{95}$.

Namely, consider the Earth system as a nonautonomous dynamical system, i.e. $\mathbf{x}=(t, \mathbf{x})$, where the governing equations $f$ depend explicitly on time. Let $(s, t)$ be its solution at time $t$, where $\mathbf{x}$ is the initial state at time $s$ (with $s \leq t$ ). In the autonomous case the system is time-translation invariant, i.e. $(s, t)=(\mathrm{t}-\mathrm{s}) \mathbf{x}$. However, in the nonautonomous case, when fixing a time $t$ ("now"), the initial time ( $s$ at which the system started becomes important, and the asymptotic behaviour occurs when $s \rightarrow-\infty$. Solutions obtained when fixing $s$ and letting $t \rightarrow \infty$, and when fixing $t$ and letting $s \rightarrow \infty$, may thus differ. In forced systems, this gives rise to the notion of a pullback attractor, which is a collection $U_{t \in \mathbb{R}}(t)$ of dynamically invariant objects $(t)$ that each attracts some initial points starting in the asymptotic past. Provided the time window $t-s$ is sufficiently larger than the typical convergence time to the attractor, this defines a family of attractors defined by the "freezing time" $t$. In this interpretation, expanding the time window corresponds to fixing $t$ in $(s, t)$ at increasing $t$, yielding a set of attractors from which to cross map. Hence, if cross mapping convergence occurs for a certain time series length in the expanding window analysis, we may adopt the pullback attractor view for any time series length beyond that. 
If time-dependent dynamical coupling existed between ASI and SCOR, this would be reflected in the pullback attractors. Thus, we would expect a change in the ability for SCOR to predict the putative ASI driver as the time window expands. This is precisely what we observe in our CCM analyses: after convergence is achieved for a sufficiently long time series, including more points does not alter convergence but changes the magnitude of the prediction skill (Fig. S4a).

\section{Expanding window analysis on Phanerozoic ASI and SCOR ara}

In Figure $2 c$ we only show the results of analyses for which convergence could be demonstrated, i.e. the windows spanning the Ordovician - late Middle Triassic (Ladinian) until the Ordovician - Late Pliocene (Piacenzian). No convergence was achieved in windows from the Ordovician - Silurian until the Ordovician - early Middle Triassic (Anisian), which we attribute to the low number of data points in these analyses. The lack of convergence in the longest window, the Ordovician - Pleistocene may be due to the weakening influence of ASI on SCOR ara and is preceded by a decrease in CCM skill throughout the Cenozoic. Despite the decline of CCM skill in the Jurassic - Early Cretaceous, intervals extending to the mid-Cretaceous - Palaeogene show a significant coupling of ASI and SCORara (Fig. 2C). The analysis in these time windows may be dominated by the stronger coupling in older time intervals, or signify a genuine, albeit weakened influence of ASI extending through to the Palaeogene. The overall declining cross mapping skill is found to be robust against the uncertainty in the stage-level $\mathrm{SCOR}_{\text {ara }}$ and ASI data (Fig. S4b), both when using the Demicco or Berner $\mathrm{Mg} / \mathrm{Ca}$ model. Significant cross mapping in any time window only occurs between SCOR ara and the combined ASI record, and not for $\mathrm{SCOR}_{\text {ara }}$ and $\mathrm{Mg} / \mathrm{Ca}$ alone, which is expected if ASI is a better measure of the abiotic forcing of SCOR ara than $\mathrm{Mg} / \mathrm{Ca}$ alone.

Lastly, we note that although using the stage level data for CCM analyses pushes the limits of the applicability of the method, we do not apply interpolation to a regular grid and introduce more data points, because that would introduce spurious dynamical information which we have no way of verifying. Rather, we assume that the sequence of stage level SCOR ara and ASI contains sufficient variability to assess the dynamical relationship between the variables on the time scales considered here. Despite the coarse-grained data, we find that the relationship between SCORara and ASI is surprisingly robust to noise and the choice of $\mathrm{Mg} / \mathrm{Ca}$ models and T records (Fig. S4b). The congruence between the linear correlation and cross mapping results supports that the covariation of SCOR ara and ASI is not merely a statistical coincidence.

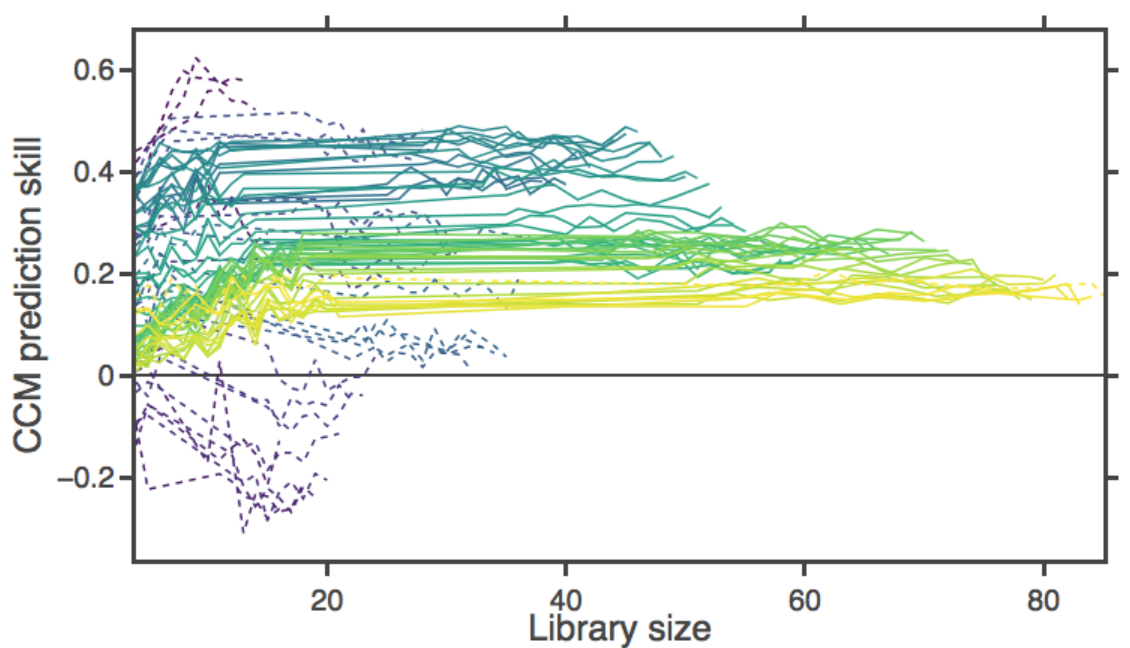

Figure S4a: CCM convergence plot for time windows of increasing length (gradient from blue to yellow), ranging from Ordovician-Silurian (blue) until the Ordovician-Pleistocene (yellow). The colour coding of the lines obeys the library size. For a 
given time window, the analysis is convergent (solid lines) if the prediction skills are higher at large library sizes than at lower library sizes, and non-convergent if not (dashed lines).
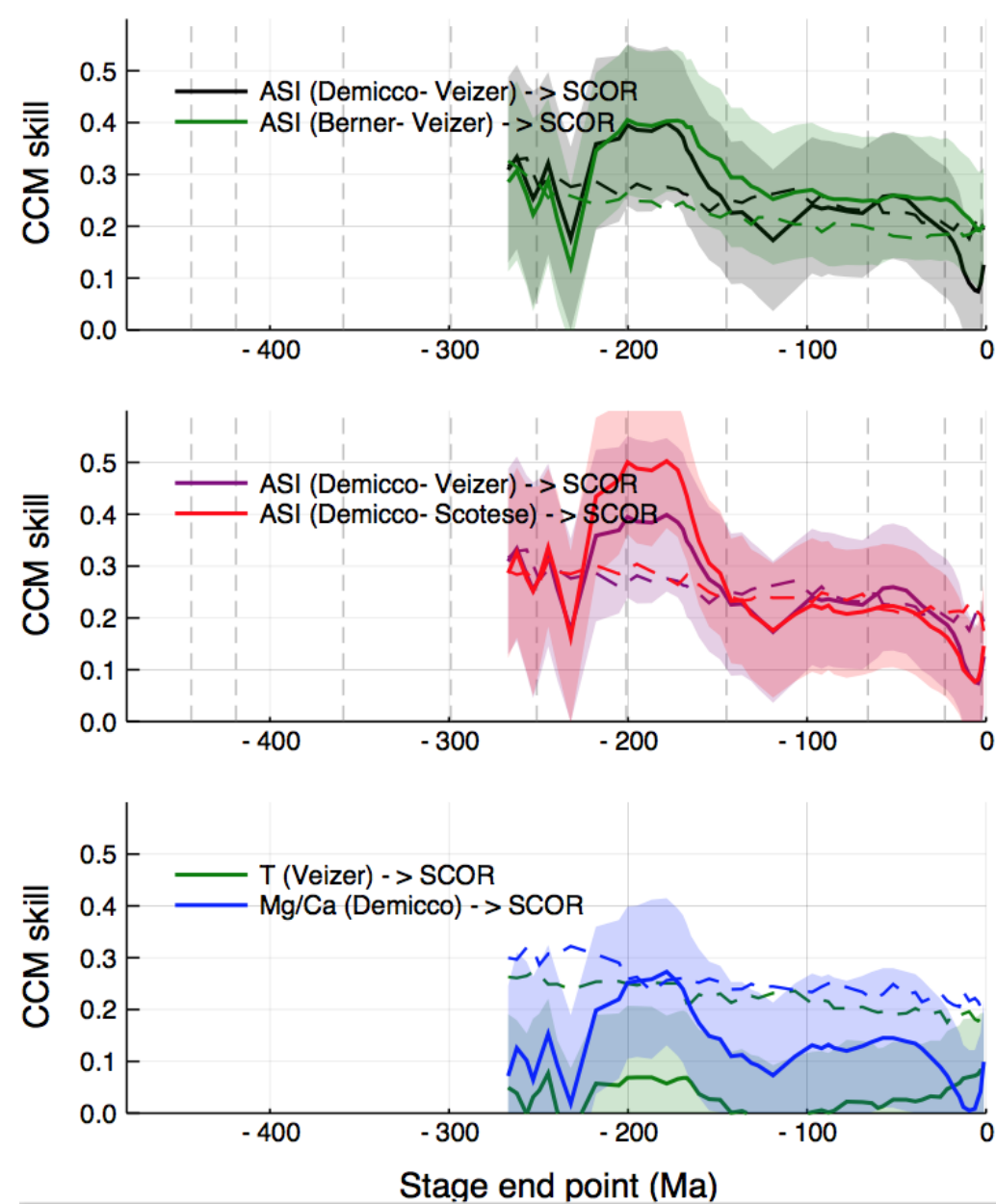

Figure S4b: Cross mapping sensitivity to uncertainty in SCOR and ASI records, and to the choice of $\mathrm{Mg} / \mathrm{Ca}$ model. Error envelopes are the standard deviation of the mean CCM skill over an ensemble of 200 random realizations of the ASI and SCOR data. Each ensemble member is constructed by drawing a random realization within the $5-95 \%$ quantile range (for SCOR) and 33-67\% quantile range (for ASI, which has much larger uncertainties) of the data uncertainties. Dashed lines are the $95^{\text {th }}$ percentiles of the median CCM skill over 300 surrogate realizations that are drawn in the same manner as the original data, but where the putative response time series is randomly shuffled. Causal interpretations (opposite of cross mapping direction) are indicated.

\section{S3. Aragonite bias}

Aragonitic shells are less likely to be preserved in the fossil record than calcitic taxa $a^{51,96,97}$. This would jeopardize the veracity of our results about the relative success of calcitic and aragonitic taxa, if the relative preservation potential of aragonite and calcite were to differ through time. To avoid temporal differences in aragonite preservation, we excluded occurrences from unlithified sediments, as those provide a different preservation potential than lithified rocks ${ }^{98}$; we also excluded all collections with aragonite preservation. Both of those preservational exceptions are predominantly found in the Cenozoic, and their inclusion might overestimate $\mathrm{SCOR}_{\text {ara }}$ in younger stages. Preservation bias against aragonitic taxa seems to be prominent in carbonates, but less significant in siliciclastic sediments ${ }^{26}$. Calculating SCOR separately in both environments thus allows us to estimate the impact of aragonite loss on our analysis: SCOR ara is lower in carbonate environments than in siliciclastic settings in 53 out 
of 85 stages (see Figure S5a). The mean ratio of carbonate : siliciclastic SCORara is 0.97 . The ratio varies through time, but is not systematically higher in older time bins (Fig. S5b): A linear model, log (SCOR ara, carbonate / SCOR ara, siliciclastic) against time, is not significant $(p=0.16)$. If older stages were more affected by aragonite loss, we would expect higher SCORara in siliciclastic settings than in carbonate settings in those stages, and a decrease of the discrepancy towards the present - i.e., a positive slope in the regression. We conclude that while an aragonite bias might affect the data within stages, it acts in a temporally consistent way, and relative changes through time are biologically meaningful.

As a second test to compare the completeness of the fossil record of aragonitic and calcitic taxa, we calculate the proportion of gaps among them ${ }^{99}$. A gap describes the absence of a genus in a stage in which it is known to have lived due to occurrences of that genus in older and younger stages. The gap proportion ( $g p$ ) of a group of genera in stage $s$ is the number of gaps $\left(g_{s}\right)$, divided by $g_{s}$ plus the number of genera actually encountered in $s\left(h_{s}\right)$ :

(1) $g p=\frac{g_{s}}{g_{s}+h_{s}}$.

The gap proportion throughout the Ordovician - Pleistocene is similar for aragonitic and calcitic taxa (Fig S6a). The median gp of aragonitic taxa is 0.41 , slightly higher than the median gp of calcitic taxa, 0.38 . A Wilcoxon signed-rank test shows that difference in ranks of aragonitic and calcitic $g p$ is not significant $(p=0.28)$.

A narrower definition of a gap is the "part-timer" ${ }^{14}$. A part-timer is a genus that is not encountered in stage $s$, but is found in the stage immediately before and in the stage immediately after $s$. We calculate the part-timer proportion (pp) in stage $s$ by dividing the number of part-timers (pt) by pt plus the number of three-timers ( $3 t$ ), i.e. the genera that were found in $s$ and in the stage immediately before and in the stage immediately after $s$ :

(2) $p(p t)=\frac{p t_{s}}{p t_{s}+3 t_{s}}$

$p p$ of aragonitic and calcitic taxa, too, are similar (Fig S6b). The median $p p$ is 0.22 for aragonitic taxa and 0.19 for calcitic taxa, and the difference is not significant when assessed with a Wilcoxon signedrank test $(p=0.52)$. 
(a)

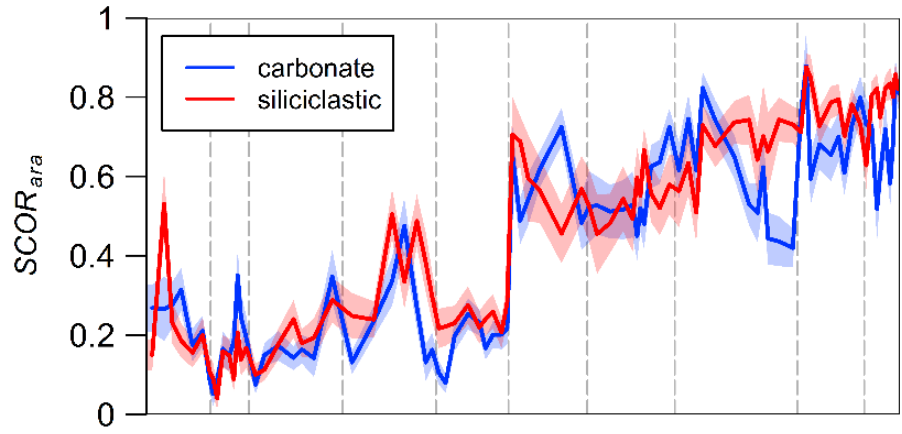

(b)

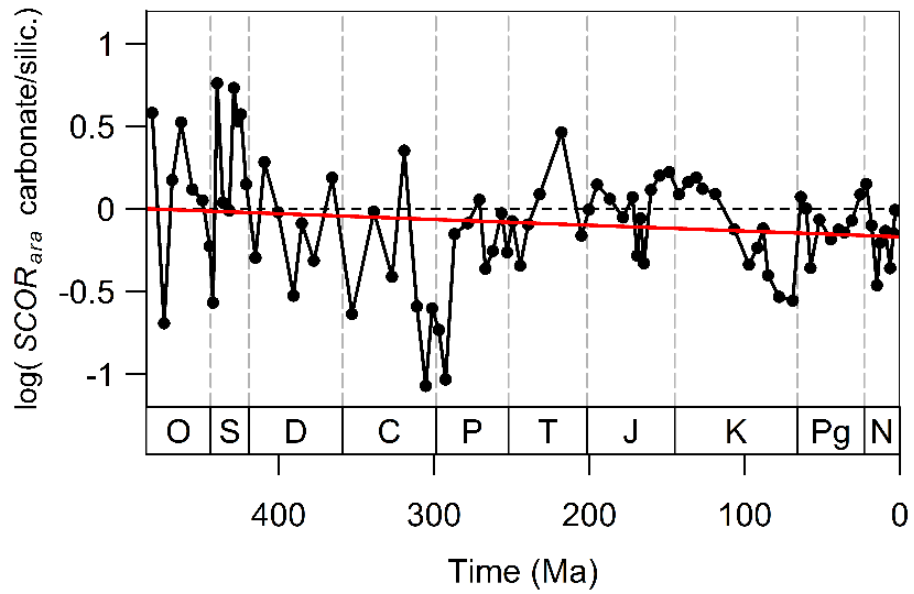

Figure S5: Carbonate vs siliciclastic settings.

(a) The relative success of aragonitic calcifiers, $\mathrm{SCOR}_{\text {ara, }}$ in carbonates (blue) and siliciclastic settings (red) in 85 Ordovician - Cenozoic stages. Shaded envelopes denote $95 \%$ confidence intervals.

(b) Natural logarithms of the ratio of the SCORara in carbonates and in siliciclastic settings,

$\log$ (SCORara, carbonate / SCORara, siliciclastic), in 85 Ordovician - Cenozoic stages. The red line shows a linear model of $\log \left(\mathrm{SCOR}_{\text {ara, carbonate }} / \mathrm{SCOR}\right.$ ara, silicilastic $)$ against time. The model is not significant $\left(R^{2}=0.02, p=0.16\right.$, intercept $=$ -0.17 , slope $=-0.00035$ )

(a)

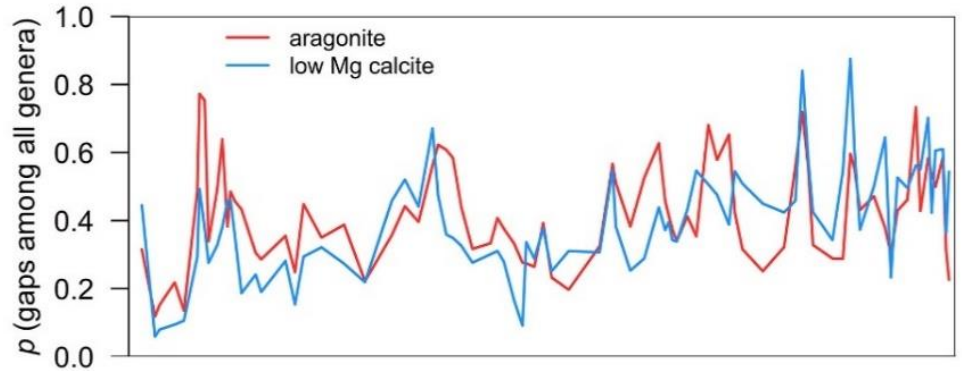

(b)

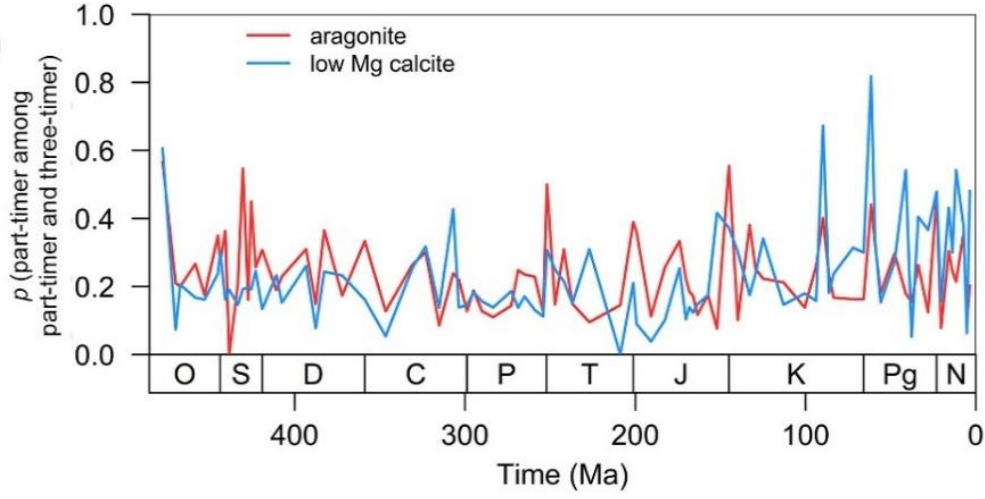

Figure S6: Sampling completeness of aragonitic and calcitic genera.

(a) Gap proportions of aragonitic and calcitic genera (sensu Paul 1982) ${ }^{99}$. For every genus, the span between their first and their last occurrence is calculated. The number of gaps in a stage $s$ is the number of genera which don't occur in $s$, but which occur in any stage before and after $s$. This gap number is divided by the sum of the number of genera that occur in stage $s$ and the gap number, to get the gap proportions.

(b) Part-timer proportions of aragonitic and calcitic genera (sensu Alroy 2014) $)^{14}$. Part-timers are genera that don't occur within stage $s$, but do occur in the stages immediately before and after $s$. The number of part-timers is divided by the number of three-timers, i.e. genera that occur in and immediately before and after stage $s$, plus the number of part-timers, to get the part-timer proportion. 


\section{S4. Unbuffered taxa}

Taxonomic groups that are thought to be more vulnerable to changes in the physiochemical environment are commonly referred to as "unbuffered" ${ }^{1}$. We expect the subset of unbuffered taxa to react to changes in ASI consistent with the patterns in the full data set, but perhaps even more strongly. We therefore calculated SCOR ara with only unbuffered taxa, following the classification of ref. 25, except we included cephalopods following ref. 2 (Table S1). The patterns seen in the entire data set are essentially confirmed in the unbuffered subset (Fig. S7), although the $\mathrm{R}^{2}$ of linear models in expanding windows are lower in most of the Palaeozoic windows, partly because models with autoregressive errors were selected from the Devonian onwards. In the Mesozoic - Cenozoic, a relationship between $\mathrm{SCOR}_{\text {ara }}$ and ASI can be inferred up to the Middle Jurassic (Fig. S7b).

Table S1: Unbuffered taxa. Selection of physiologically unbuffered taxa is based on ref. 25. We added Cephalopods following ref. 2.

\begin{tabular}{l|l}
\hline Higher taxon & remark \\
\hline Cephalopods & excluding Nautilida \\
Epifaunal Bivalves & \\
Stenolaemate bryozoans & \\
Cheilostome bryozoans & \\
Corals & \\
Ostracods & \\
Calcifying sponges & \\
Foraminifera & \\
Calcareous algae & \\
Rhynchonelliform brachiopods & \\
Echinoderms &
\end{tabular}


(a)
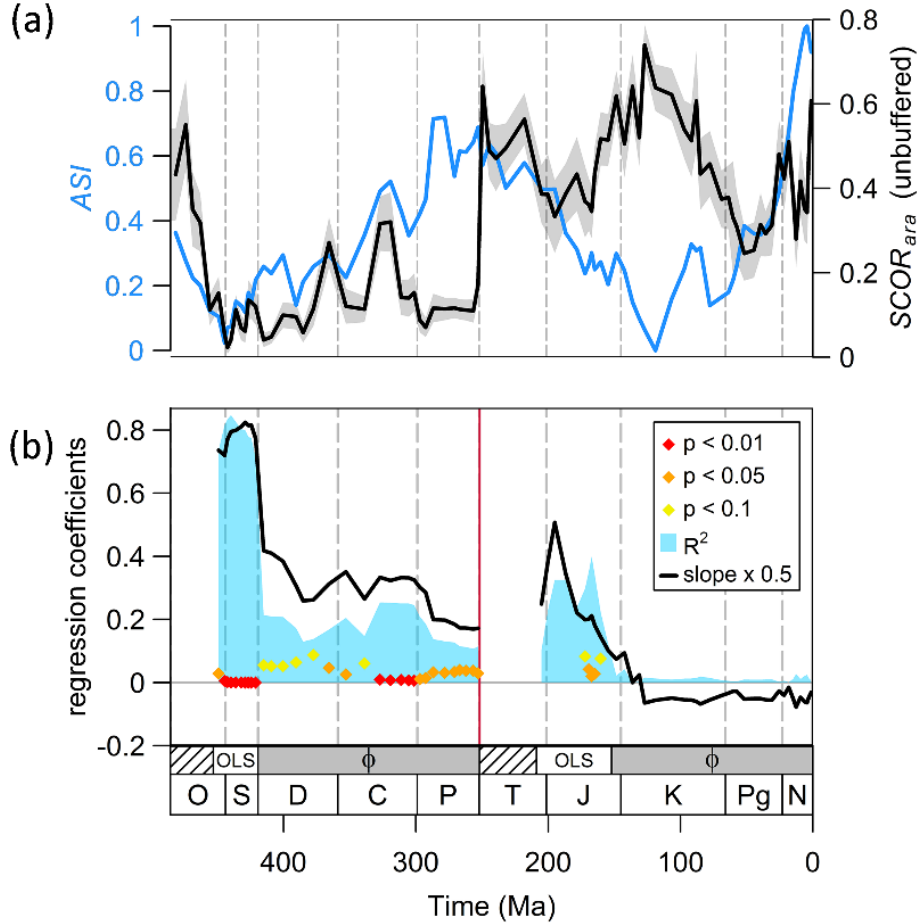

Figure S7: SCOR ara of unbuffered taxa and aragonite sea intensity (ASI).

(a) ASI (blue) and the relative success of aragonitic calcifiers, SCOR ara, in the subset of unbuffered taxa (black) in 85 Ordovician Pleistocene stages. The grey envelope indicates the $95 \%$ confidence interval of SCOR $\mathrm{R}_{\text {ara. }}$.

(b) Linear models of SCORara in the subset of unbuffered taxa against ASI in windows of increasing length in the Palaeozoic and in the Mesozoic - Cenozoic, separately. Slope (black) and $\mathrm{R}^{2}$ (blue) of each model are drawn at the last included stage of the respective window. $p$-values are only shown when they are $<0.1$. All Palaeozoic models start at the first Ordovician stage (Tremadocian), and all Mesozoic - Cenozoic models start with the Early Triassic (Induan). The box at the bottom shows whether the models were generated using ordinary least squares (OLS), or generalised least squares with autoregressive errors of the first order ( $\phi)$. No models were calculated for intervals with five or less stages (hatched pattern).

\section{S5. Major taxonomic groups}

Bivalves, brachiopods, gastropods, cephalopods and corals are the most common calcifying clades in the data set. For every stage, we evaluated clade success through time by dividing the SCOR of the taxonomic group of interest by the SCOR of all calcifiers. Changes in the relative SCOR of taxonomic groups are thus always influenced by simultaneous changes in the success of other calcifying groups. For individual groups, a smaller amount of data is available than for the entirety of aragonitic calcifiers, which leads to more volatile patterns of group success through time. This makes estimating the extent of ASI influence on the SCOR of individual taxonomic groups less reliable than the analysis with $\mathrm{SCOR}_{\text {ara, }}$ but several interesting patterns emerge nonetheless.

Brachiopods. Calcifying brachiopods are calcitic, with the exception of the trimellerids, which are aragonitic $^{52}$ and are not included in the brachiopod subset. Brachiopod SCOR is calculated among the subset of benthic taxa. Brachiopods were the most successful calcifying clade from the late Ordovician to the End-Permian mass extinction. They retained a moderate SCOR until the Middle Jurassic, and almost continuously declined thereafter (Fig. S8a). Brachiopod SCOR and ASI have a significant negative linear relationship over much of the Ordovician - Carboniferous (Figure S8a). The relationship disappears with the addition of the Permian, presumably due to the high $\mathrm{CaCO}_{3}$ supersaturation of the ocean at that time. After the Jurassic, brachiopods were excluded from most shallow water, 
benthic communities despite calcite sea conditions. Ecological interactions with competitors such as bivalves, rather than environmental changes, may have been the cause of this decline ${ }^{100}$.

Bivalves. Bivalves build either purely aragonitic shells, or shells comprised of aragonitic and calcitic layers ${ }^{101}$. If the proportion of calcite in the shells exceeds $90 \%$, we treat them as calcitic (see ref. 25 for a detailed description of how mineralogies were assigned). Bivalve shell mineralogy is largely determined by phylogeny: Palaeoheterodonta, Protobranchia and taxa of unknown affinity are exclusively aragonitic, as are most non-rudist Heterodonta (Fig. S9). Most Pteriomorphia are bimineralic, with e.g. oysters having many dominantly calcitic taxa ${ }^{101}$. We calculated separately the success of aragonitic, calcitic and bimineralic bivalves relative to all calcifying taxa, only including benthic occurrences (Fig. S8e-g). A positive linear relationship between the SCOR of aragonitic bivalves and ASI is evident in the Palaeozoic (Fig. S8e). The negative relationship of aragonitic bivalves and ASI inferred for the Triassic - Early Cretaceous is probably spurious and disappears in the linear models in which autocorrelation is considered.

Patterns in the SCOR of bimineralic bivalves are difficult to interpret. In the Devonian - Carboniferous, and less robustly also in the Mesozoic, their SCOR is positively correlated with ASI. We did not include the Ordovician - Silurian, as bivalves with calcitic shell layers are rare or absent during much of the Ordovician and Silurian. In contrast, an earlier study reported a Phanerozoic correspondence between calcite seas and diversity increases of bivalves with calcitic shell layers ${ }^{20}$. The majority of these partly calcitic bivalves are included in our bimineralic subset. Considering ASI rather than the binary aragonite sea - calcite sea state, we cannot confirm a positive relationship between bimineralic bivalve SCOR and calcite sea conditions.

The success of dominantly calcitic bivalves could only be evaluated in the Mesozoic-Cenozoic, as they were rare in the Palaeozoic. Calcitic bivalves were most successful during the Jurassic - Cretaceous, and the Middle Jurassic - Cretaceous is an interval of relatively low ASI (Fig. S8f). A negative linear relationship of calcitic bivalve SCOR and ASI is significant in intervals extending up to the Early Cretaceous and disappears thereafter.

There is some evidence that pteriomorphs exert more control over the secretion of calcite prisms than heterodont bivalves ${ }^{102}$, and the only time when bimineralic heterodonts were successful was during the Cretaceous calcite sea (Fig. S9d). Calcitic pteriomorphs, too, were most successful during the Jurassic and Cretaceous, but calcitic pteriomorph SCOR rose in the Triassic and Early Jurassic aragonite sea (Fig. S9c). The overall relative SCOR of heterodonts and pteriomorphs among all bivalves seems to be unrelated to aragonite-calcite sea conditions (Fig. S9a).

The quantitative evidence for a relationship of bivalve SCOR with ASI remains ambiguous. The dominant pattern in the history of bivalves is a long-lasting increase in success, especially following the end-Permian extinction.

Gastropods. Gastropods are mostly aragonitic, and we excluded all taxa with calcitic shell layers comprising $>10 \%$ of the total shell for the calculation of gastropod SCOR. Analysis was carried out only among benthic taxa. A positive linear relationship of gastropod SCOR and aragonite sea intensity is significant in some intervals in the Ordovician - Carboniferous, weakens in the Permian, and no relationship can be inferred in the Mesozoic - Cenozoic (Fig. S8b).

Cephalopods. Cephalopod SCOR was calculated without the calcitic belemnites. Due to the extinction of most shelled cephalopods at the Cretaceous - Palaeogene boundary, Cenozoic stages were not included in the linear models. The linear relationship between the SCOR of cephalopods relative to all calcifiers and ASI is strong in the Palaeozoic, but not significant in the Mesozoic (Fig S8c). The decreased response of Mesozoic cephalopods to aragonite-calcite sea conditions may have to do with the extinction of most Palaeozoic cephalopods at the end-Permian mass extinction: Ammonoids were 
the dominant clade of Mesozoic cephalopods, and almost all of their Mesozoic members were descendants of a few survivors ${ }^{103}$. It is possible that the surviving ammonoids were less susceptible to physiochemical changes than Palaeozoic cephalopods on average, as the end-Permian extinction selectively favoured survival of physiologically buffered taxa ${ }^{28}$.

Corals. Corals were analysed separately in the Palaeozoic and the Mesozoic - Cenozoic. Palaeozoic corals, Tabulata and Rugosa, were calcitic, whereas scleractinian corals are aragonitic. Corals occur preferentially in carbonate settings. To avoid distortion of temporal patterns of coral SCOR by changing abundances of occurrences from carbonate and siliciclastic settings, respectively, we calculated coral SCOR only in carbonate settings and only included benthic occurrences in the analysis as in ref. 25. Corals were rare in the Early - Middle Ordovician and modern corals only appeared in the Middle Triassic; hence we excluded the Early - Middle Ordovician and Early - Middle Triassic when estimating models of coral SCOR against ASI.

Contrary to expectations, of the main taxonomic groups, corals show the least response to changing ASI (Fig. S8d). The linear models of coral SCOR against ASI are not significant in the Palaeozoic. In the Triassic - Cretaceous until the Triassic - Palaeogene, significant relationships with a negative slope persist. However, if aragonite-calcite seas influenced the success of aragonitic corals, ASI should be positively correlated with coral SCOR. Calcification of modern corals is aided by photosymbiosis, and is biologically controlled to a high degree ${ }^{104}$, and some Palaeozoic corals may have harboured photosymbionts as well ${ }^{105}$. However, experiments showed a strong decrease of scleractinian coral growth under calcite sea conditions ${ }^{106}$. Scleractinian skeletal mineralogy can be influenced by $\mathrm{Mg} / \mathrm{Ca}$ ratio and temperature, although mostly higher aragonite proportions than predicted by the inorganic $\mathrm{CaCO}_{3}$ system were retained in experiments ${ }^{17}$. The lack of a long-term influence of aragonite-calcite sea conditions on the SCOR of corals may stem from the affinity of corals to reef settings. Reefs are hotspots of evolution, diversity and biotic interactions ${ }^{107}$, and they may well be a hotspot for biotically, rather than environmentally controlled evolution. The Phanerozoic fossil record of reefs exhibits a "boom and bust pattern" that cannot be explained by secular environmental changes ${ }^{108}$. 

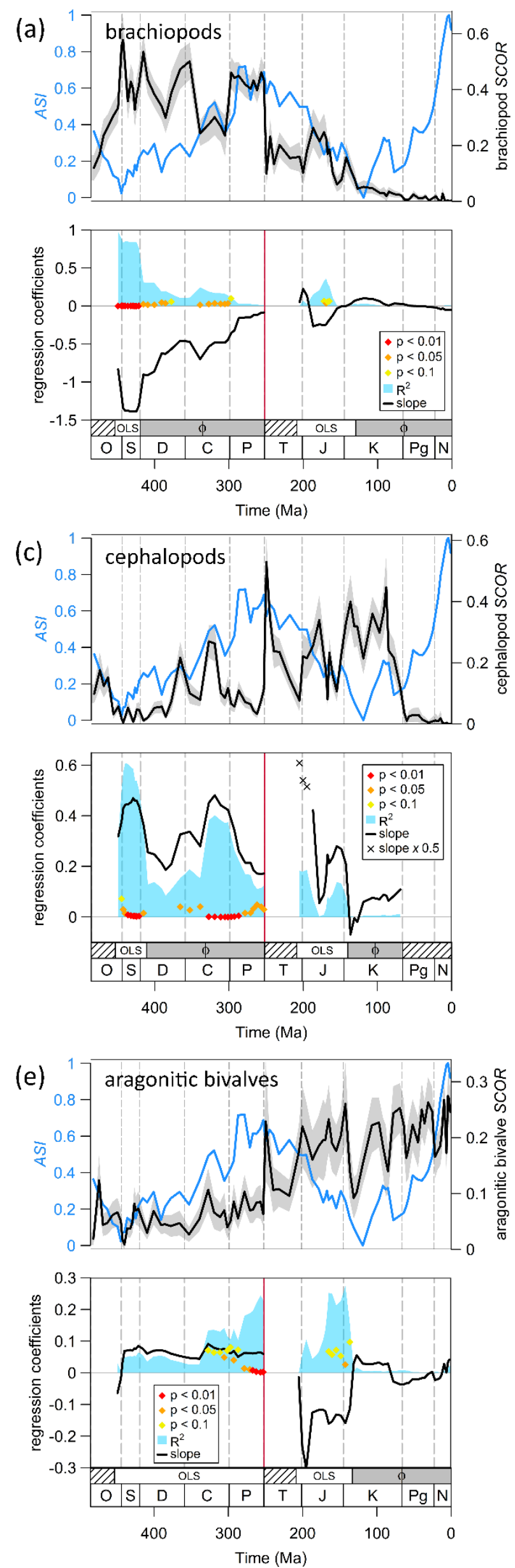
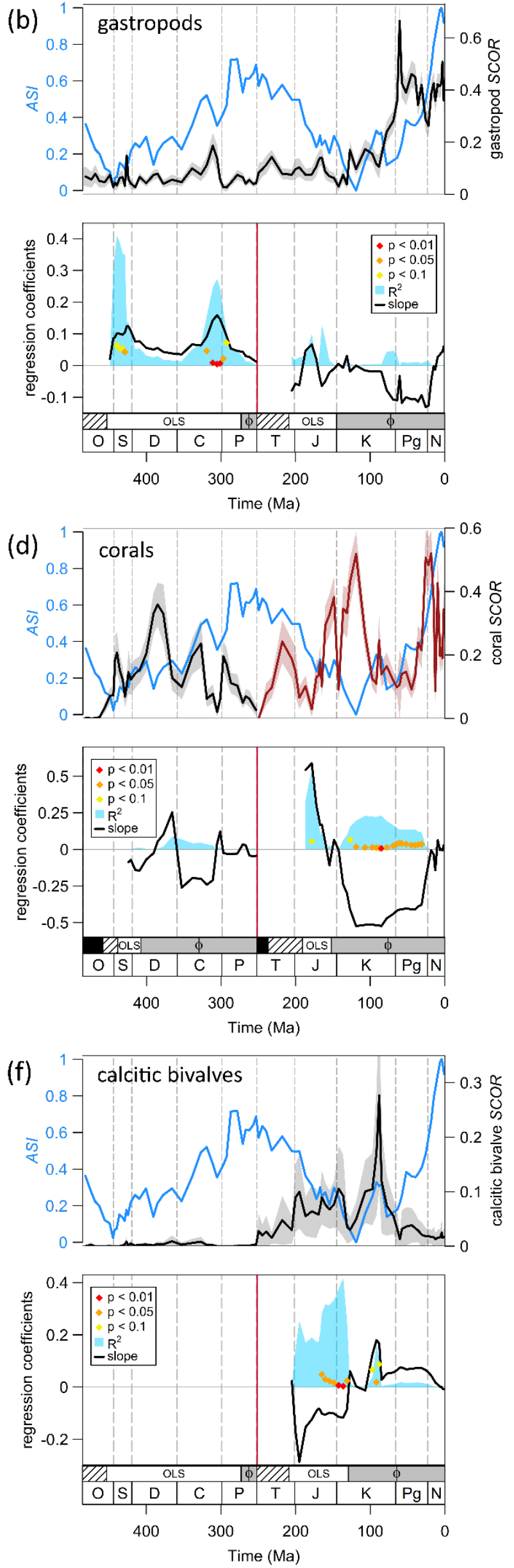

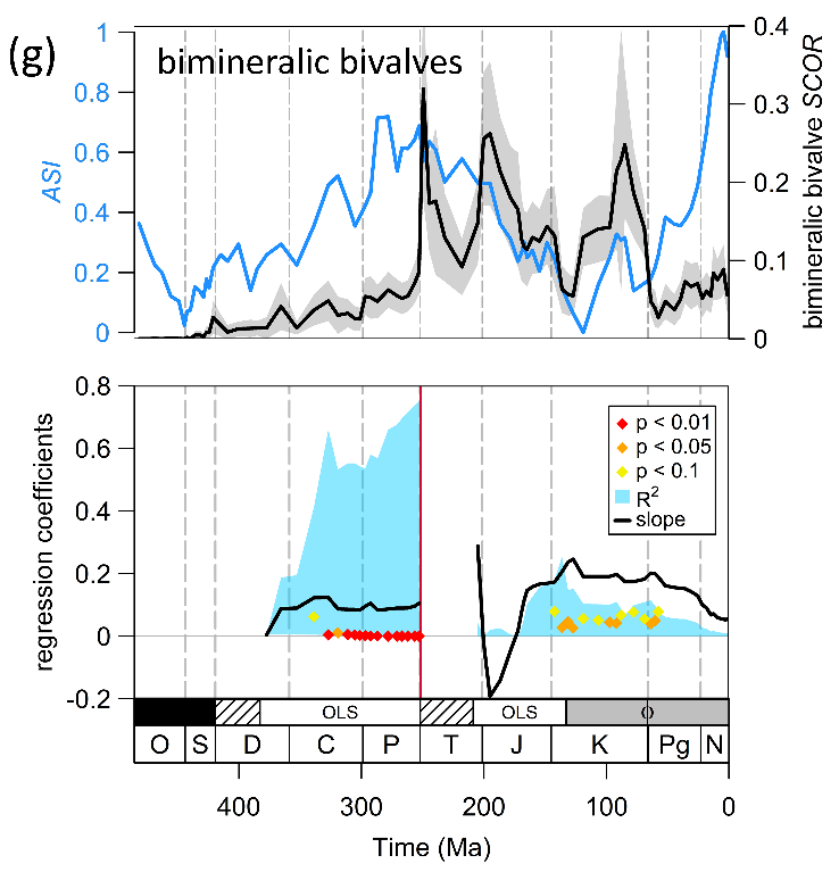

Figure S8a-g: Relative SCOR of major taxonomic groups (brachiopods, gastropods, cephalopods, corals, bivalves), and linear models with ASI.

Upper figures: Aragonite sea intensity (blue) and the relative success of a major taxonomic group, SCOR (black) in 85 Ordovician - Cenozoic stages. The grey or red envelope indicates $1.96 \times$ standard error of SCOR.

Bottom figures: Linear models of the SCOR of taxonomic groups against ASI in windows of increasing length in the Palaeozoic and in the Mesozoic Cenozoic, separately. Slope (black) and $\mathrm{R}^{2}$ (blue) of each model are drawn at the last included stage of the respective window. $p$-values are only shown when they are < 0.1. All Palaeozoic models start at the first Ordovician stage (Tremadocian), and all Mesozoic - Cenozoic models start with the Early Triassic (Induan). The box at the bottom shows whether the models were generated using ordinary least squares (OLS), or generalised least squares with autoregressive errors of the first order $(\phi)$. No models were calculated for intervals with five or less stages (hatched pattern).

(a) Brachiopod SCOR includes only calcitic brachiopods. The analysis was carried out with only benthic taxa.

(b) Gastropod SCOR includes only aragonitic gastropods. The analysis was carried out with only benthic taxa.

(c) Cephalopod SCOR includes only aragonitic cephalopods (i.e., belemnites were excluded).

(d) Corals. Palaeozoic coral SCOR includes only calcitic corals, and the Lower - Middle Ordovician are excluded from the linear model. Mesozoic Cenozoic coral SCOR includes only aragonitic corals, and the Lower - Middle Triassic are excluded from the linear models. The analyses were carried out with occurrences only from carbonate environments, and only with benthic taxa.

(e) Aragonitic bivalve SCOR includes bivalves with > $90 \%$ aragonite in their skeleton. The analysis was carried out with only benthic taxa.

(f) Calcitic bivalve SCOR includes bivalves with > $90 \%$ calcite in their skeleton. Only the Mesozoic - Cenozoic model is estimated, due to the rarity of dominantly calcitic bivalves in the Palaeozoic. The analysis was carried out with only benthic taxa.

(g) Bimineralic bivalve SCOR includes bivalves with $>10 \%$ aragonite and $>10 \%$ calcite in their skeleton. The Ordovician - Silurian are excluded from the linear model. The analysis was carried out with only benthic taxa. 
(a)

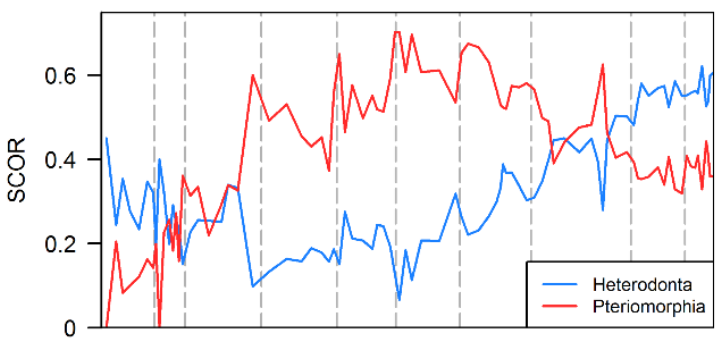

(c)

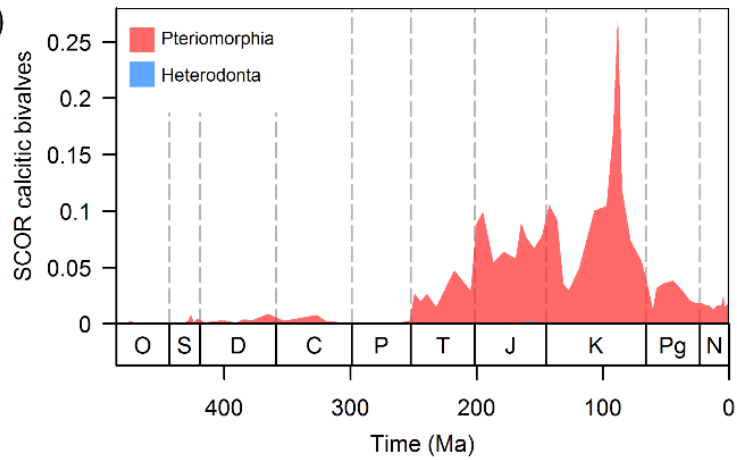

(b)

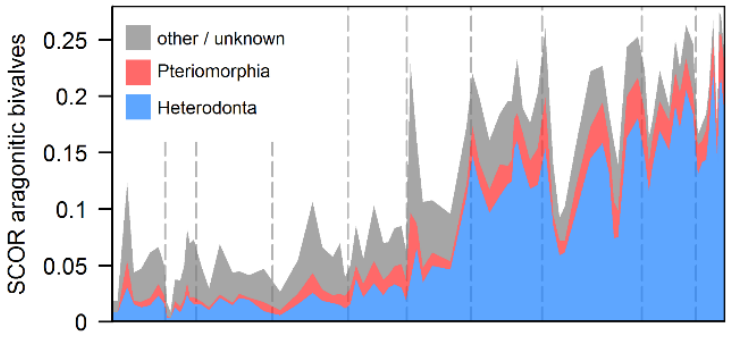

(d)

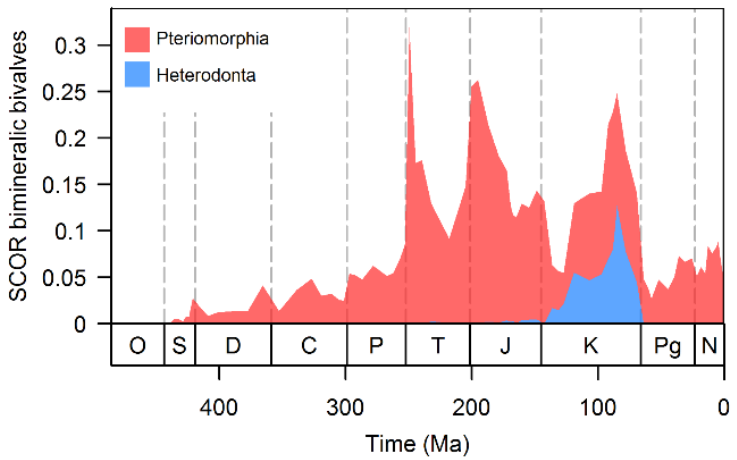

\section{Figure S9: Bivalve subclasses.}

(a) Relative SCOR of the two dominant bivalve subclasses among all bivalves: Heterodonta (blue), and Pteriomorphia (red).

(b) SCOR of aragonitic bivalves as in Fig. S8e, broken down into bivalves subclasses. The contribution to SCOR of Heterodonta (blue), Pteriomorphia (red), and other or unknown bivalve subclasses (grey) are shown.

(c) SCOR of calcitic bivalves as in Fig. S8f, broken down into bivalves subclasses. Only Pteriomorphia (red) contribute to SCOR, except for a minor contribution of Heterodonta (blue) in the Upper Jurassic.

(d) SCOR of bimineralic bivalves as in Fig. S8g, broken down into bivalves subclasses. Only Pteriomorphia (red) and Heterodonta (blue) contribute to SCOR. 


\section{S6. De novo acquisition of skeletons and changes in skeletal mineralogy}

\section{De novo acquisition}

The skeletal mineralogy of clades of marine calcifiers is in most cases determined by the seawater composition of the time at which the clade first evolved a skeleton ${ }^{21,109,110}$. These de novo acquisitions of skeletons have the potential to shift SCOR ara without necessarily changing the real ecological success of involved taxa, as the newly calcifying taxa might have been successful even before secreting mineralised hard parts.

Novel acquisitions of mineralised hard parts are rare - Porter (2010) lists 40 acquisition events of calcium carbonate skeletons ranging from the Ediacaran - Palaeogene, most of them concentrated in the early Palaeozoic ${ }^{21}$. Of the major clades composing our data set, molluscs, calcifying brachiopods, trilobites and echinoderms acquired their skeleton already in the Cambrian, and those together make up $79 \%$ of the total occurrences in our data (Fig. S10, Table S2). The de novo acquisitions of their skeleton thus cannot drive the patterns seen in $\mathrm{SCOR}_{\text {ara. }}$ Of the remaining occurrences in our data, $13 \%$ belong to taxa that acquired their calcareous skeletons during the Ordovician, which minimises their potential impact on the observed Jurassic decoupling of ASI and SCORara. A further $4.9 \%$ of the occurrences in the data set are from taxa evolving a skeleton in the Triassic - Palaeogene, the large majority of those occurrences are scleractinian corals (4.3\%) which originated in the Middle Triassic. Demosponges and calcifying red and green algae make up most of the remaining $2.6 \%$ of occurrences, and those cannot be assigned to a single timing of skeletal origin ${ }^{111-113}$.

To test whether the Mesozoic patterns in the relationship of ASI and SCOR ara are driven by skeletal acquisitions, we removed all groups that acquired a skeleton de novo in the Mesozoic or Cenozoic ${ }^{21}$ and calculated SCOR ara with only the remaining taxa (Fig. S11a). The taxa excluded for this analysis are scleractinian corals, cheilostomate bryozoans and several other, rare taxonomic groups. The resulting correlation (Fig. S11b) is very similar to results obtained for the total dataset (Fig. 2b). The timing of de novo skeletal acquisitions therefore cannot explain the early Mesozoic correlation and later decoupling of SCORara and ASI.
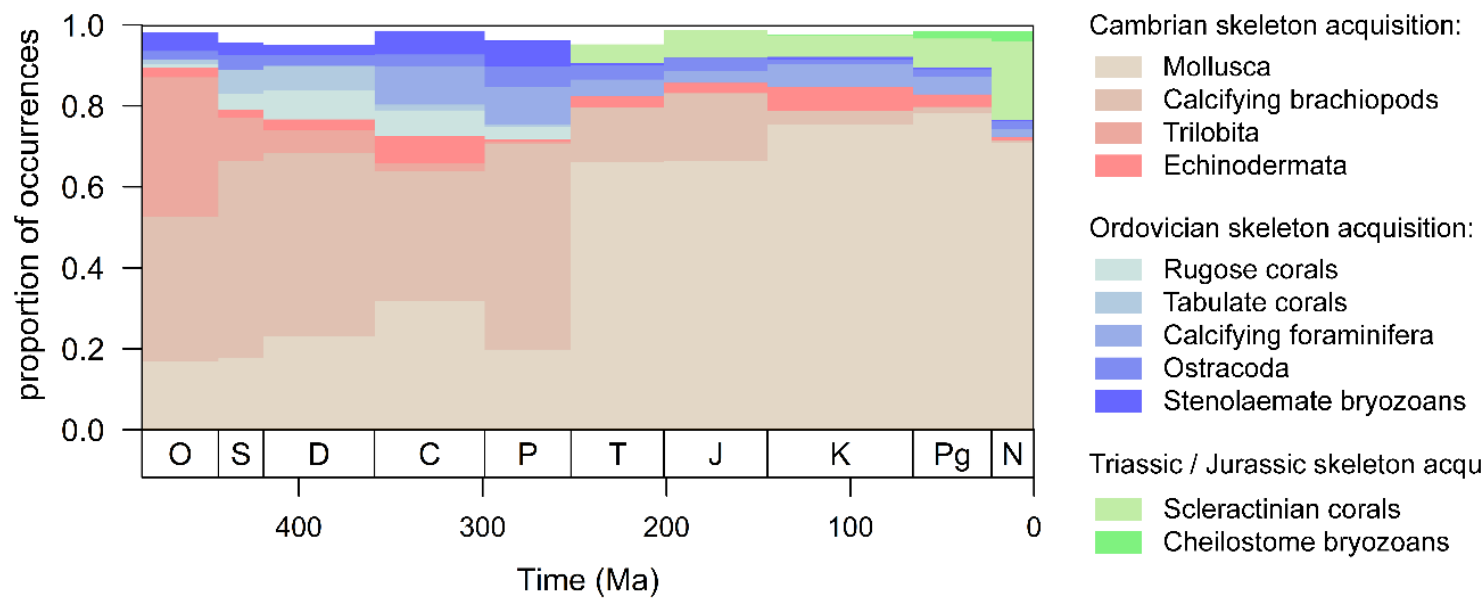

Triassic / Jurassic skeleton acquisition:

Scleractinian corals Cheilostome bryozoans

\section{Figure S10: Frequency of major calcifying clades}

Proportions of occurrences of major calcifying groups in the PBDB data set in geological periods. The group proportions are displayed in order of their evolutionary acquisition of a calcium carbonate skeleton ${ }^{21,114}$ : Clades with a Cambrian origin of their skeleton are shown in beige - red, an Ordovician origin is denoted with blue colours, and clades with a Triassic (scleractinian corals) or Jurassic (cheilostome bryozoans) skeletal acquisition are shown in green. 

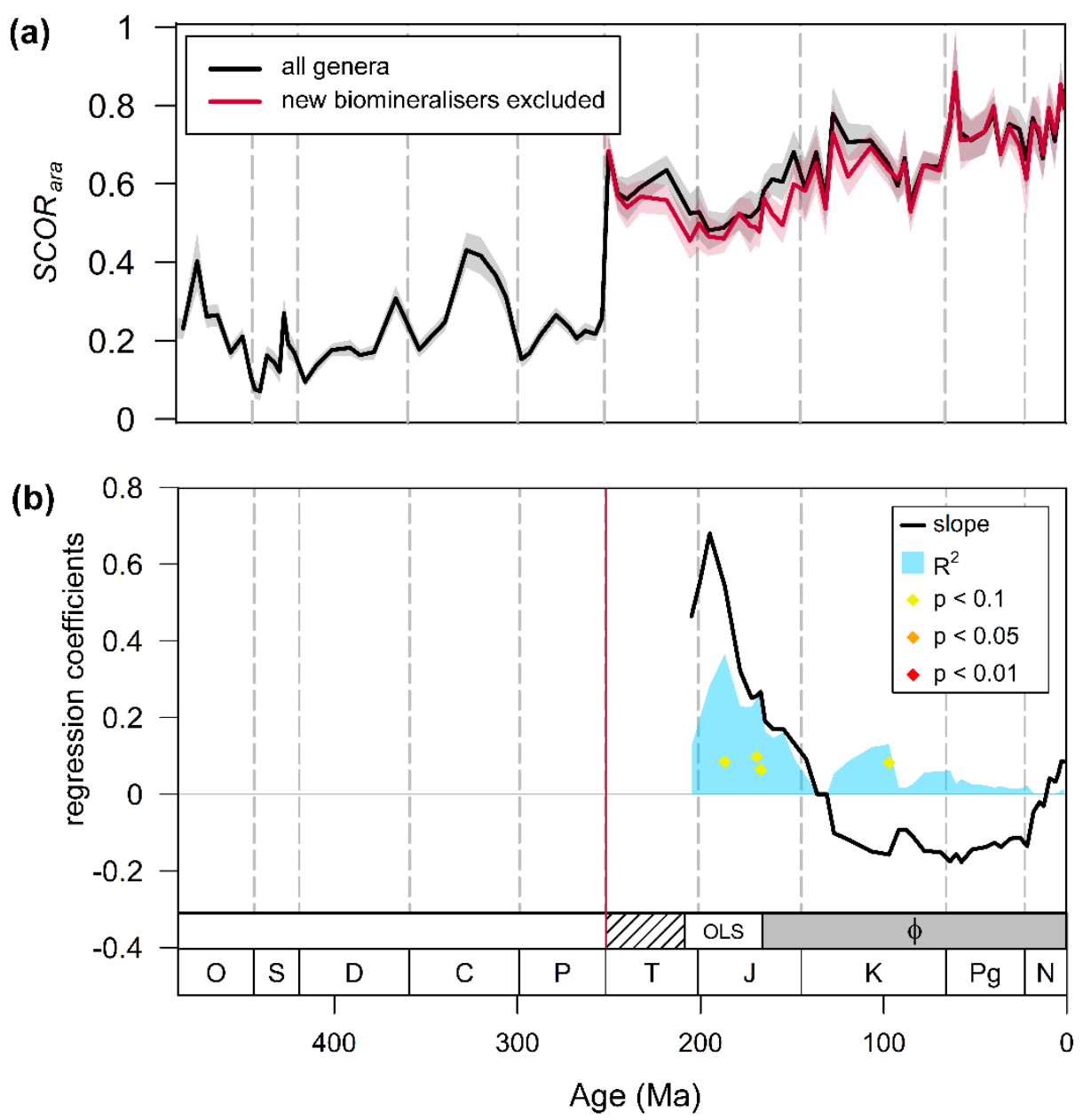

Figure S11a: SCORara without originating genera and aragonite sea intensity (ASI).

(a) Relative success of aragonitic calcifiers, SCORara, of all genera (black) and of genera excluding taxa that acquired their skeletons in the Mesozoic or Cenozoic (red), respectively, in 85 Ordovician - Pleistocene stages. The excluded taxa comprise Scleractinia, cheilostomate bryozoans, serpulid worms and several other anthozoan orders. The envelopes indicate $95 \%$ confidence intervals. (b) Linear models of SCORara excluding Mesozoic and Cenozoic skeletal acquisitions as in (a), against ASI in windows of increasing length in the Mesozoic - Cenozoic. Slope (black) and $\mathrm{R}^{2}$ (blue) of each model are drawn at the last included stage of the respective window. $p$ values are only shown when they are $<0.1$. All models start with the Early Triassic (Induan). The box at the bottom shows whether the models were generated using ordinary least squares (OLS), or generalised least squares with autoregressive errors of the first $\operatorname{order}(\phi)$. No models were calculated for intervals with five or less stages (hatched pattern). The pattern is very similar to that in Fig. 2b with the SCOR ara of all genera. 
Table S2: Timing of de novo acquisition and contribution to our dataset

Most taxa in our data set evolved their skeleton in the Cambrian, Ordovician or in the Triassic - Jurassic. These taxa

and the percentage they constitute in our entire Ordovician - Pleistocene data set are listed below. The $\mathrm{CaCO}_{3}$

skeletons of calcifying algae and demosponges have multiple evolutionary origins ${ }^{111-113}$, and a further $0.97 \%$ of

remaining occurrences has origins in the middle - late Palaeozoic, or an origin could not be assigned.

\begin{tabular}{|c|c|c|}
\hline Taxon & Skeletal acquisition & Occurrences \% \\
\hline Mollusca & Cambrian & 48.1 \\
\hline Calcifying brachiopods & Cambrian & 25.0 \\
\hline Trilobita & Cambrian & 3.28 \\
\hline Echinodermata & Cambrian & 2.90 \\
\hline Calcarea & Cambrian & 0.09 \\
\hline Hyolitha & Cambrian & 0.04 \\
\hline total & Cambrian & 79.32 \\
\hline Calcifying foraminifera & Ordovician & 4.55 \\
\hline Ostracoda & Ordovician & 2.93 \\
\hline Stenolaemate bryozoans & Ordovician & 2.53 \\
\hline Rugose corals & Ordovician & 2.03 \\
\hline Tabulate corals & Ordovician & 1.11 \\
\hline Machaeridia & Ordovician & 0.01 \\
\hline total & Ordovician & 13.16 \\
\hline Scleractinian corals & Triassic & 4.31 \\
\hline Cheilostome bryozoans & Jurassic & 0.39 \\
\hline other & Mesozoic-Cenozoic & 0.18 \\
\hline total & Mesozoic - Cenozoic & 4.88 \\
\hline Demospongia & & 1.00 \\
\hline Chlorophyta & & 0.36 \\
\hline Rhodophyta & & 0.29 \\
\hline other & & 0.97 \\
\hline total & various & 2.62 \\
\hline
\end{tabular}

\section{2a. Changes in skeletal composition and SCOR ara}

Changes in skeletal mineralogy after a clade had acquired a specific skeletal composition are a second possibility of how SCOR ara could change without an actual change in the ecological success of the constituent taxa. With the exception of some bivalve and cheilostome genera, skeletal mineralogy tends to be consistent within families, and more so within genera (see section $2 b$ below.). A SCOR ara time series with minimal contribution from changing skeletal mineralogies can thus be generated by excluding newly evolved genera from the data set (Fig. S12a). The resulting curve is very similar to the $\mathrm{SCOR}_{\text {ara }}$ of the full data set, and although the correlation with ASI is somewhat weaker in the Palaeozoic, it shows the same temporal pattern of a decoupling between SCOR ara and ASI (Fig. S12b). Thus neither de novo acquisition of calcareous skeletons, nor changes of mineral composition within calcifying clades can account for the overall patterns of correlation between ecological success and aragonite sea intensity. 


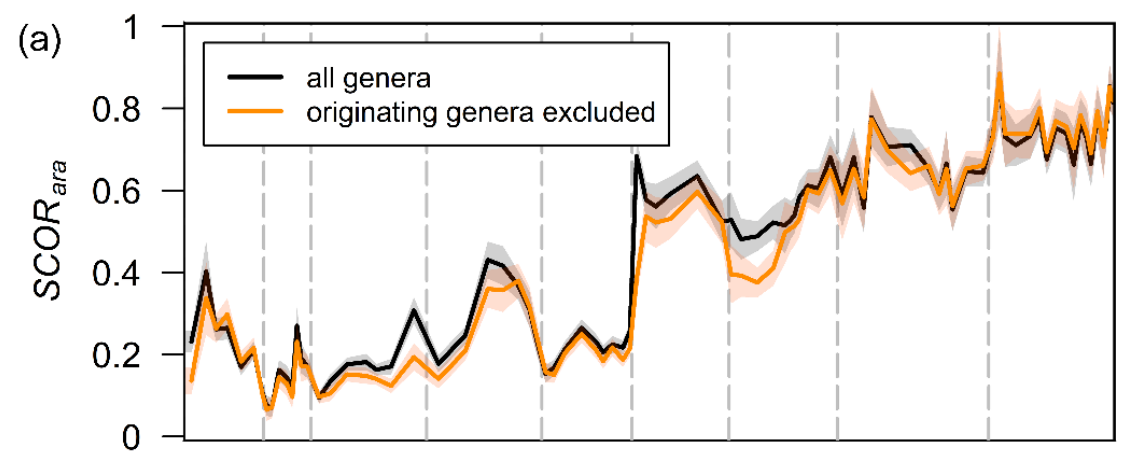

(b)

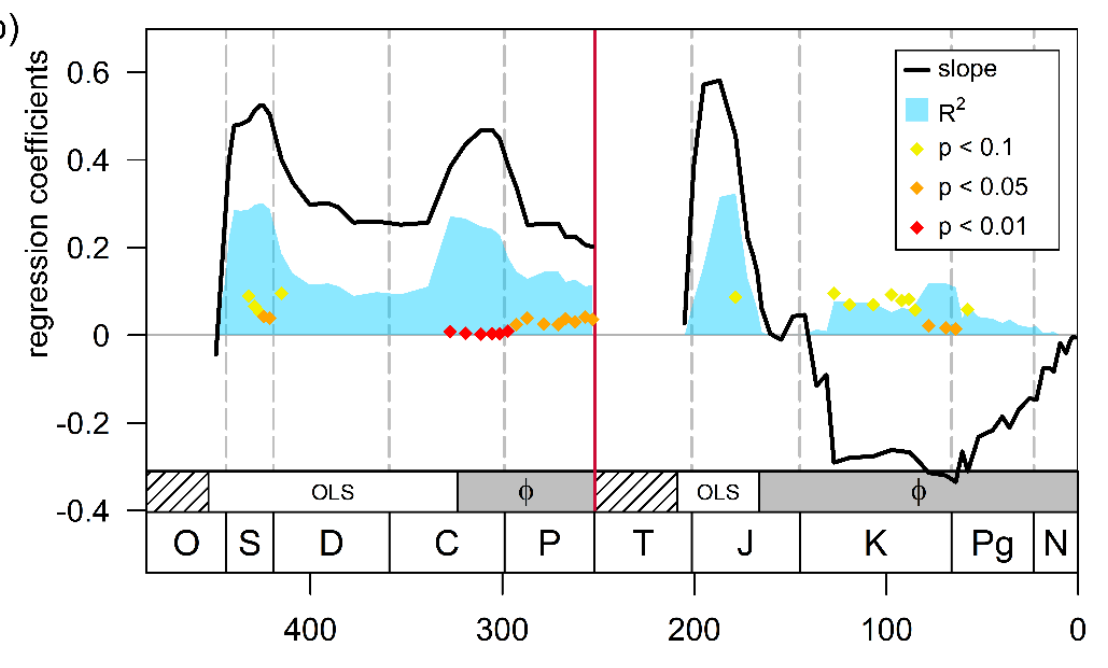

Age (Ma)

Figure S12: SCOR ${ }_{\text {ara }}$ without originating genera and aragonite sea intensity (ASI).

(a) Relative success of aragonitic calcifiers, SCOR ara, of all genera (black) and genera excluding first appearances (originating, orange), respectively, in 85 Ordovician - Pleistocene stages. The envelopes indicate $95 \%$ confidence intervals.

(b) Linear models of SCORara without originating genera against ASI in windows of increasing length in the Palaeozoic and in the Mesozoic - Cenozoic, separately. Slope (black) and $\mathrm{R}^{2}$ (blue) of each model are drawn at the last included stage of the respective window. $p$-values are only shown when they are $<0.1$. All Palaeozoic models start at the first Ordovician stage (Tremadocian), and all Mesozoic - Cenozoic models start with the Early Triassic (Induan). The box at the bottom shows whether the models were generated using ordinary least squares (OLS), or generalised least squares with autoregressive errors of the first order $(\phi)$. No models were calculated for intervals with five or less stages (hatched pattern). The pattern is very similar to that in Fig. $2 \mathrm{~b}$, which includes originating data.

\section{2b. Mineralogy changes in major clades}

In cheilostome bryozoans, foraminifers, gastropods and especially in bivalves, multiple taxa have changed their skeletal mineralogy, commonly by the addition of a shell layer with a different mineralogy ${ }^{20,114-117}$. In gastropods, significant skeletal calcite content is concentrated within a limited range of families and genera ${ }^{69}$. The skeletal mineralogy of foraminifers can be resolved well along higher taxonomic divisions ${ }^{114,118}$. In bivalves, the addition of calcitic shell layers to an originally aragonitic skeleton has evolved several times. Skeletal mineralogies are consistent within the majority of bivalve families ${ }^{119}$, although e.g. the mineralogy of bivalves in the genus Mytilus differs between species and individuals in different habitats ${ }^{120}$. Similarly, some cheilostome bryozoans have siginificant mineralogical differences within genera ${ }^{115}$. In most major clades, however, changes in mineralogy are rare: trilobites, echinoderms, ostracods are exclusively calcitic, and brachiopods and stenolaemate bryozoans are generally calcitic, with the exception of trimerellid brachiopods ${ }^{52}$ and a few genera of Stenolaemata with minor skeletal aragonite content ${ }^{115}$. Ammonoids, nautiloids and scleractinian corals are, with rare exceptions in the latter two groups ${ }^{121-123}$, aragonitic. 


\section{S7. Data cleaning and data summary}

To resolve incomplete higher taxonomies of individual occurrences in the Paleobiology Database, we used taxonomic information from other PBDB occurrences and, when available, from the World Register of Marine Species (WoRMS) ${ }^{124}$ using the taxize package ${ }^{125}$.

Hierarchical assignments as implemented in the PBDB where used to fill in missing skeletal mineralogies, and the skeletal composition of several higher taxa was corrected following ref. 25 and references therein. Occurrences were excluded if the skeletal composition could not be resolved or if the occurrences could not be assigned to a genus. All filters that were applied to clean the data are listed in Table S3. The final data set comprises 398,199 occurrences. The number of occurrences and genera in every stage are given in Table S4.

Table S3: Data cleaning. Criteria based on which we excluded PBDB occurrences, and links to relevant information regarding these criteria in the PBDB.

\begin{tabular}{l|l} 
Criterion & Category and reference to definitions \\
\hline Marine & Palaeoenvironment (http://paleodb.org/public/tips/environtips.html) \\
\hline Identified to genus level & Taxonomy (http://paleodb.org/trac/log/html/public/tips/taxontips.html?rev=748) \\
\hline $\begin{array}{l}\text { Is an invertebrate animal, or Foraminifera, } \\
\text { Chlorophyta, Rhodophyta, or calcifying } \\
\text { "Problematica" }\end{array}$ & Taxonomy \\
\hline Is not plankton & Taxonomy, life habits (http://paleodb.org/public/tips/ecology_tips.html) \\
\hline $\begin{array}{l}\text { Assignable to an Ordovician - Pleistocene } \\
\text { stage }\end{array}$ & Stratigraphy (http://paleodb.org/public/tips/tips.html) \\
\hline No aragonite preservation recorded & Preservation (http://paleodb.org/public/tips/tips.html) \\
\hline Lithology not "unlithified" & Lithology (http://paleodb.org/public/tips/tips.html) \\
\hline Palaeocoordinates available & \\
\hline Is calcifying & Skeletal mineralogy (ref. 25)
\end{tabular}


Table S4: Data summary. Number of genera, occurrences, and occurrences per million year for every stage of the final PBDB data set. The Induan and Olenekian are treated as one stage, as well as the four Pleistocene stages. Ages of the stage boundaries are taken from Gradstein et al. 2012; some ages have been updated following Cohen et al. 2013

\begin{tabular}{|c|c|c|c|c|c|c|}
\hline period & stage & $\begin{array}{c}\text { lower stage } \\
\text { boundary (myr) }\end{array}$ & duration & genera & occurrences & occurrences/myr \\
\hline \multirow[t]{7}{*}{ Ordovician } & Tremadocian & 485.4 & 7.7 & 590 & 3556 & 462 \\
\hline & Floian & 477.7 & 7.7 & 258 & 935 & 121 \\
\hline & Dapingian & 470 & 2.7 & 621 & 3195 & 1183 \\
\hline & Darriwilian & 467.3 & 8.9 & 728 & 3464 & 389 \\
\hline & Sandbian & 458.4 & 5.4 & 779 & 4768 & 883 \\
\hline & Katian & 453 & 7.8 & 840 & 5626 & 721 \\
\hline & Hirnantian & 445.2 & 1.4 & 423 & 2361 & 1686 \\
\hline \multirow[t]{8}{*}{ Silurian } & Rhuddanian & 443.8 & 3.0 & 257 & 1561 & 520 \\
\hline & Aeronian & 440.8 & 2.3 & 332 & 1360 & 591 \\
\hline & Telychian & 438.5 & 5.1 & 549 & 2345 & 460 \\
\hline & Sheinwoodian & 433.4 & 2.9 & 455 & 1947 & 671 \\
\hline & Homerian & 430.5 & 3.1 & 411 & 1236 & 399 \\
\hline & Gorstian & 427.4 & 1.8 & 419 & 1224 & 680 \\
\hline & Ludfordian & 425.6 & 2.6 & 412 & 1638 & 630 \\
\hline & Pridoli & 423 & 3.8 & 488 & 1740 & 458 \\
\hline \multirow[t]{7}{*}{ Devonian } & Lochkovian & 419.2 & 8.4 & 780 & 4485 & 534 \\
\hline & Pragian & 410.8 & 3.2 & 881 & 3484 & 1089 \\
\hline & Emsian & 407.6 & 14.3 & 1193 & 5740 & 401 \\
\hline & Eifelian & 393.3 & 5.6 & 879 & 4425 & 790 \\
\hline & Givetian & 387.7 & 5.0 & 1107 & 15750 & 3150 \\
\hline & Frasnian & 382.7 & 10.5 & 622 & 7149 & 681 \\
\hline & Famennian & 372.2 & 13.3 & 654 & 3767 & 283 \\
\hline \multirow[t]{7}{*}{$\begin{array}{l}\text { Carbonifer } \\
\text { ous }\end{array}$} & Tournaisian & 358.9 & 12.2 & 703 & 3899 & 320 \\
\hline & Visean & 346.7 & 15.8 & 905 & 8955 & 567 \\
\hline & Serpukhovian & 330.9 & 7.7 & 573 & 3238 & 421 \\
\hline & Bashkirian & 323.2 & 8.0 & 495 & 2584 & 323 \\
\hline & Moscovian & 315.2 & 8.2 & 626 & 3869 & 472 \\
\hline & Kasimovian & 307 & 3.3 & 401 & 1930 & 585 \\
\hline & Gzhelian & 303.7 & 4.8 & 509 & 3988 & 831 \\
\hline \multirow[t]{9}{*}{ Permian } & Asselian & 298.9 & 3.9 & 677 & 4498 & 1153 \\
\hline & Sakmarian & 295 & 4.9 & 806 & 6469 & 1320 \\
\hline & Artinskian & 290.1 & 6.6 & 1000 & 6902 & 1046 \\
\hline & Kungurian & 283.5 & 10.6 & 1125 & 11438 & 1084 \\
\hline & Roadian & 272.95 & 4.2 & 1078 & 8769 & 2113 \\
\hline & Wordian & 268.8 & 3.7 & 1009 & 8070 & 2181 \\
\hline & Capitanian & 265.1 & 6.0 & 1017 & 8683 & 1447 \\
\hline & Wuchiapingian & 259.1 & 5.0 & 1019 & 11473 & 2313 \\
\hline & Changhsingian & 254.14 & 2.2 & 925 & 10353 & 4626 \\
\hline \multirow[t]{6}{*}{ Triassic } & Induan + Olenekian & 251.902 & 4.7 & 608 & 9733 & 2070 \\
\hline & Anisian & 247.2 & 5.2 & 664 & 6879 & 1323 \\
\hline & Ladinian & 242 & 5.0 & 521 & 2369 & 474 \\
\hline & Carnian & 237 & 10.0 & 824 & 4120 & 412 \\
\hline & Norian & 227 & 18.2 & 902 & 5022 & 276 \\
\hline & Rhaetian & 208.8 & 7.5 & 540 & 3607 & 481 \\
\hline
\end{tabular}




\begin{tabular}{|c|c|c|c|c|c|c|}
\hline period & stage & $\begin{array}{c}\text { lower stage } \\
\text { boundary (myr) }\end{array}$ & duration & genera & occurrences & occurrences/myr \\
\hline \multirow[t]{11}{*}{ Jurassic } & Hettangian & 201.3 & 2.0 & 296 & 1744 & 872 \\
\hline & Sinemurian & 199.3 & 8.5 & 401 & 3167 & 373 \\
\hline & Pliensbachian & 190.8 & 8.1 & 589 & 11608 & 1433 \\
\hline & Toarcian & 182.7 & 8.6 & 472 & 9064 & 1054 \\
\hline & Aalenian & 174.1 & 3.8 & 334 & 2438 & 642 \\
\hline & Bajocian & 170.3 & 2.0 & 584 & 3577 & 1788 \\
\hline & Bathonian & 168.3 & 2.2 & 624 & 4534 & 2061 \\
\hline & Callovian & 166.1 & 2.6 & 757 & 6969 & 2680 \\
\hline & Oxfordian & 163.5 & 6.2 & 785 & 6292 & 1015 \\
\hline & Kimmeridgian & 157.3 & 5.2 & 637 & 4002 & 770 \\
\hline & Tithonian & 152.1 & 7.1 & 668 & 4069 & 573 \\
\hline \multirow[t]{12}{*}{ Cretaceous } & Berriasian & 145 & 5.2 & 348 & 1405 & 270 \\
\hline & Valanginian & 139.8 & 6.9 & 442 & 2309 & 335 \\
\hline & Hauterivian & 132.9 & 3.5 & 421 & 2349 & 671 \\
\hline & Barremian & 129.4 & 4.4 & 600 & 2132 & 485 \\
\hline & Aptian & 125 & 12.0 & 782 & 3513 & 293 \\
\hline & Albian & 113 & 12.5 & 1006 & 6690 & 535 \\
\hline & Cenomanian & 100.5 & 6.6 & 936 & 7521 & 1140 \\
\hline & Turonian & 93.9 & 4.1 & 621 & 4276 & 1043 \\
\hline & Coniacian & 89.8 & 3.5 & 308 & 1344 & 384 \\
\hline & Santonian & 86.3 & 2.7 & 597 & 2857 & 1058 \\
\hline & Campanian & 83.6 & 11.5 & 980 & 7304 & 635 \\
\hline & Maastrichtian & 72.1 & 6.1 & 1139 & 14114 & 2314 \\
\hline \multirow[t]{9}{*}{ Palaeogene } & Danian & 66 & 4.4 & 907 & 3826 & 870 \\
\hline & Selandian & 61.6 & 2.4 & 391 & 1014 & 423 \\
\hline & Thanetian & 59.2 & 3.2 & 544 & 1876 & 586 \\
\hline & Ypresian & 56 & 8.2 & 892 & 4167 & 508 \\
\hline & Lutetian & 47.8 & 6.6 & 803 & 2689 & 407 \\
\hline & Bartonian & 41.2 & 3.4 & 972 & 5523 & 1624 \\
\hline & Priabonian & 37.8 & 3.9 & 1324 & 6334 & 1624 \\
\hline & Rupelian & 33.9 & 5.8 & 906 & 4670 & 805 \\
\hline & Chattian & 28.1 & 5.1 & 880 & 3816 & 753 \\
\hline \multirow[t]{8}{*}{ Neogene } & Aquitanian & 23.03 & 2.6 & 434 & 1017 & 393 \\
\hline & Burdigalian & 20.44 & 4.5 & 861 & 2418 & 541 \\
\hline & Langhian & 15.97 & 2.2 & 635 & 1559 & 725 \\
\hline & Serravallian & 13.82 & 2.2 & 764 & 2295 & 1048 \\
\hline & Tortonian & 11.63 & 4.4 & 716 & 3058 & 698 \\
\hline & Messinian & 7.246 & 1.9 & 630 & 2914 & 1523 \\
\hline & Zanclean & 5.333 & 1.7 & 1051 & 4510 & 2602 \\
\hline & Piacenzian & 3.6 & 1.0 & 1045 & 4700 & 4608 \\
\hline Quaternary & Pleistocene & 2.58 & 2.6 & 1347 & 9931 & 3867 \\
\hline
\end{tabular}




\section{Supplementary References}

2 Bambach, R. K., Knoll, A. H. \& Sepkoski, J. J. Anatomical and ecological constraints on Phanerozoic animal diversity in the marine realm. Proceedings of the National Academy of Sciences 99, 6854-6859 (2002).

10 Sandberg, P. A. An oscillating trend in Phanerozoic non-skeletal carbonate mineralogy. Nature 305, 19-22 (1983). Alroy, J. Accurate and precise estimates of origination and extinction rates. Paleobiology 40, 374-397 (2014).

16 Hardie, L. A. Secular variation in seawater chemistry: An explanation for the coupled secular variation in the mineralogies of marine limestones and potash evaporites over the past 600 my. Geology 24, 279-283 (1996).

17 Higuchi, T., Shirai, K., Mezaki, T. \& Yuyama, I. Temperature dependence of aragonite and calcite skeleton formation by a scleractinian coral in low mMg/Ca seawater. Geology 45, 1087-1090 (2017). Harper, E. M., Palmer, T. J. \& Alphey, J. Evolutionary response by bivalves to changing Phanerozoic sea-water chemistry. Geological Magazine 134, 403-407 (1997).

21 Porter, S. Calcite and aragonite seas and the de novo acquisition of carbonate skeletons. Geobiology 8, 256-277 (2010).

22 Demicco, R. V., Lowenstein, T. K., Hardie, L. A. \& Spencer, R. J. Model of seawater composition for the Phanerozoic. Geology 33, 877-880 (2005).

Veizer, J. \& Prokoph, A. Temperatures and oxygen isotopic composition of Phanerozoic oceans. EarthScience Reviews 146, 92-104 (2015). Kiessling, W., Aberhan, M. \& Villier, L. Phanerozoic trends in skeletal mineralogy driven by mass extinctions. Nature Geoscience 1, 527-530 (2008). Foote, M., Crampton, J. S., Beu, A. G. \& Nelson, C. S. Aragonite bias, and lack of bias, in the fossil record: lithological, environmental, and ecological controls. Paleobiology 41, 245-265 (2015). Sugihara, G. et al. Detecting causality in complex ecosystems. science, 1227079 (2012).

28 Knoll, A. H., Bambach, R. K., Payne, J. L., Pruss, S. \& Fischer, W. W. Paleophysiology and end-Permian mass extinction. Earth and Planetary Science Letters 256, 295-313 (2007). Cherns, L. \& Wright, V. P. Quantifying the impacts of early diagenetic aragonite dissolution on the fossil record. Palaios 24, 756-771 (2009).

52 Balthasar, U. et al. Relic aragonite from Ordovician-Silurian brachiopods: Implications for the evolution of calcification. Geology 39, 967-970 (2011). Alroy, J. et al. Phanerozoic trends in the global diversity of marine invertebrates. Science 321, 97-100 (2008).

72 Lowenstein, T. K., Timofeeff, M. N., Brennan, S. T., Hardie, L. A. \& Demicco, R. V. Oscillations in Phanerozoic seawater chemistry: Evidence from fluid inclusions. Science 294, 1086-1088 (2001). Lowenstein, T. K., Timofeeff, M. N., Kovalevych, V. M. \& Horita, J. The major-ion composition of Permian seawater. Geochimica et Cosmochimica Acta 69, 1701-1719 (2005).

74 Horita, J., Zimmermann, H. \& Holland, H. D. Chemical evolution of seawater during the Phanerozoic: Implications from the record of marine evaporites. Geochimica et Cosmochimica Acta 66, 3733-3756 (2002). past 36 million years from fluid inclusions in marine halite. American Journal of Science 313, 713-775 (2013).

76 Coggon, R. M., Teagle, D. A., Smith-Duque, C. E., Alt, J. C. \& Cooper, M. J. Reconstructing past seawater $\mathrm{Mg} / \mathrm{Ca}$ and $\mathrm{Sr} / \mathrm{Ca}$ from mid-ocean ridge flank calcium carbonate veins. Science 327, 11141117 (2010).

77 Dickson, J. Echinoderm skeletal preservation: calcite-aragonite seas and the $\mathrm{Mg} / \mathrm{Ca}$ ratio of Phanerozoic oceans. Journal of Sedimentary Research 74, 355-365 (2004).

78 Dickson, J. Fossil echinoderms as monitor of the $\mathrm{Mg} / \mathrm{Ca}$ ratio of Phanerozoic oceans. Science 298, 1222-1224 (2002).

79 Ries, J. B. Effect of ambient $\mathrm{Mg} / \mathrm{Ca}$ ratio on $\mathrm{Mg}$ fractionation in calcareous marine invertebrates: $\mathrm{A}$ record of the oceanic Mg/Ca ratio over the Phanerozoic. Geology 32, 981-984 (2004).

80 Steuber, T. \& Rauch, M. Evolution of the $\mathrm{Mg} / \mathrm{Ca}$ ratio of Cretaceous seawater: implications from the composition of biological low-Mg calcite. Marine Geology 217, 199-213 (2005). 

response to seawater chemistry: Pliocene-Pleistocene seawater $\mathrm{Mg} / \mathrm{Ca}$, temperature and sea level change. Earth and Planetary Science Letters 438, 139-148 (2016).

82 Evans, D. \& Müller, W. Deep time foraminifera Mg/Ca paleothermometry: Nonlinear correction for secular change in seawater Mg/Ca. Paleoceanography 27 (2012). Gorzelak, P., Stolarski, J., Mazur, M. \& Meibom, A. Micro-to nanostructure and geochemistry of extant crinoidal echinoderm skeletons. Geobiology 11, 29-43 (2013). Kołbuk, D., Dubois, P., Stolarski, J. \& Gorzelak, P. Effects of seawater chemistry (Mg2+/Ca2+ ratio) and diet on the skeletal $\mathrm{Mg} / \mathrm{Ca}$ ratio in the common sea urchin Paracentrotus lividus. Marine Environmental Research (2019). Gorzelak, P., Krzykawski, T. \& Stolarski, J. Diagenesis of echinoderm skeletons: constraints on paleoseawater Mg/Ca reconstructions. Global and Planetary Change 144, 142-157 (2016). Berner, R. A. A model for calcium, magnesium and sulfate in seawater over Phanerozoic time. American Journal of Science 304, 438-453 (2004). Farkaš, J. et al. Calcium isotope record of Phanerozoic oceans: Implications for chemical evolution of seawater and its causative mechanisms. Geochimica et Cosmochimica Acta 71, 5117-5134 (2007). carbon chemistry and ocean ventilation. Chemical Geology 362, 287-304 (2013). Gaffin, S. Ridge volume dependence on seafloor generation rate and inversion using long term sealevel change. American Journal of Science 287, 596-611 (1987). Brennan, S. T., Lowenstein, T. K. \& Horita, J. Seawater chemistry and the advent of biocalcification. Geology 32, 473-476 (2004).

91 Brennan, S. T. \& Lowenstein, T. K. The major-ion composition of Silurian seawater. Geochimica et Cosmochimica Acta 66, 2683-2700 (2002).

92 Timofeeff, M. N., Lowenstein, T. K., Da Silva, M. A. M. \& Harris, N. B. Secular variation in the major-ion chemistry of seawater: Evidence from fluid inclusions in Cretaceous halites. Geochimica et Cosmochimica Acta 70, 1977-1994 (2006). Alberti, M., Fürsich, F. T., Abdelhady, A. A. \& Andersen, N. Middle to Late Jurassic equatorial seawater temperatures and latitudinal temperature gradients based on stable isotopes of brachiopods and oysters from Gebel Maghara, Egypt. Palaeogeography, palaeoclimatology, palaeoecology 468, 301313 (2017). Scotese, C. in GSA Annual Meeting Denver, Colorado, Abstracts with Programs. 74-31. Chekroun, M. D., Simonnet, E. \& Ghil, M. Stochastic climate dynamics: Random attractors and timedependent invariant measures. Physica D: Nonlinear Phenomena 240, 1685-1700 (2011). Cherns, L. \& Wright, V. P. Missing molluscs as evidence of large-scale, early skeletal aragonite dissolution in a Silurian sea. Geology 28, 791-794 (2000). Wright, V. P. \& Cherns, L. How far did feedback between biodiversity and early diagenesis affect the nature of Early Palaeozoic sea floors? Palaeontology 59, 753-765 (2016).

98 Hendy, A. J. The influence of lithification on Cenozoic marine biodiversity trends. Paleobiology 35, 5162 (2009).

99 Paul, C. R. C. in Problems of phylogenetic reconstruction (Academic Press, 1982).

100 Liow, L. H., Reitan, T. \& Harnik, P. G. Ecological interactions on macroevolutionary time scales: clams and brachiopods are more than ships that pass in the night. Ecology letters 18, 1030-1039 (2015). Carter, J. Environmental and biological controls of bivalve shell mineralogy and microstructure. Skeletal growth of aquatic organisms (1980).

102 Harper, E. M. \& Checa, A. Physiological versus Biological Control in Bivalve Calcite Prisms: Comparison of Euheterodonts and Pteriomorphs. The Biological Bulletin 232, 19-29 (2017).

103 Teichert, C. Times of crisis in the evolution of the Cephalopoda. Paläontologische Zeitschrift 60, 227243 (1986).

104 Von Euw, S. et al. Biological control of aragonite formation in stony corals. Science 356, 933-938 (2017).

105 Zapalski, M. K. Evidence of photosymbiosis in Palaeozoic tabulate corals. Proceedings of the Royal Society of London B: Biological Sciences 281, 20132663 (2014).

106 Ries, J. B., Stanley, S. M. \& Hardie, L. A. Scleractinian corals produce calcite, and grow more slowly, in artificial Cretaceous seawater. Geology 34, 525-528 (2006).

107 Kiessling, W., Simpson, C. \& Foote, M. Reefs as cradles of evolution and sources of biodiversity in the Phanerozoic. Science 327, 196-198 (2010). 
109 Porter, S. M. Seawater chemistry and early carbonate biomineralization. Science 316, 1302-1302 (2007).

110 Zhuravlev, A. Y. \& Wood, R. A. Eve of biomineralization: Controls on skeletal mineralogy. Geology 36, 923-926 (2008).

111 Knoll, A. H. Biomineralization and evolutionary history. Reviews in mineralogy and geochemistry 54, 329-356 (2003).

112 Reitner, J. A new calcitic sphinctozoan sponge belonging to theDemospongiae from the Cassian Formation (Lower Carnian; Dolomites, Northern Italy) and its phylogenetic relationship. Geobios 20, 571-589 (1987).

113 Wray, J. L. in Introduction to marine Micropaleontology 171-187 (Elsevier, 1998).

114 Martin, R. E. Cyclic and secular variation in microfossil biomineralization: clues to the biogeochemical evolution of Phanerozoic oceans. Global and Planetary Change 11, 1-23 (1995).

115 Smith, A. M., Key, M. M. \& Gordon, D. P. Skeletal mineralogy of bryozoans: taxonomic and temporal patterns. Earth-Science Reviews 78, 287-306 (2006).

116 Bandel, K. Shell structure of the Gastropoda excluding Archaeogastropoda. Skeletal biomineralization: patterns, processes and evolutionary trends 1, 117-134 (1990).

117 van Dijk, I., de Nooijer, L. J., Hart, M. B. \& Reichart, G. J. The long-term impact of magnesium in seawater on foraminiferal mineralogy: Mechanism and consequences. Global Biogeochemical Cycles 30, 438-446 (2016).

118 Tappan, H. \& Loeblich Jr, A. R. Foraminiferal evolution, diversification, and extinction. Journal of Paleontology, 695-714 (1988).

119 Carter, J. G., Barrera, E. \& Tevesz, M. J. Thermal potentiation and mineralogical evolution in the Bivalvia (Mollusca). Journal of Paleontology 72, 991-1010 (1998).

120 Lowenstam, H. A. Factors affecting the aragonite: calcite ratios in carbonate-secreting marine organisms. The Journal of Geology 62, 284-322 (1954).

121 Stolarski, J., Meibom, A., Przeniosło, R. \& Mazur, M. A Cretaceous scleractinian coral with a calcitic skeleton. Science 318, 92-94 (2007).

122 De Baets, K. \& Munnecke, A. Evidence for Palaeozoic orthoconic cephalopods with bimineralic shells. Palaeontology (2017).

123 Janiszewska, K., Mazur, M., Escrig, S., Meibom, A. \& Stolarski, J. Aragonitic scleractinian corals in the Cretaceous calcitic sea. Geology 45, 319-322 (2017).

124 Horton, T. et al. World Register of Marine Species (WoRMS). WoRMS Editorial Board, http://www.marinespecies.org (2018).

125 Chamberlain, S. A. \& Szöcs, E. taxize: taxonomic search and retrieval in R. F1000Research 2, http://f1000research.com/articles/2-191/v2 (2013).

126 Gradstein, F. M., Ogg, J. G., Schmitz, M. \& Ogg, G. The geologic time scale 2012. (elsevier, 2012).

127 Cohen, K., Finney, S., Gibbard, P. \& Fan, J.-X. The ICS international chronostratigraphic chart. Episodes 36, 199-204 (2013, updated). 